Review

\title{
Engineering aspects of hydrothermal pretreatment: From batch to continuous operation, scale-up and pilot reactor under biorefinery concept
}

${ }^{a}$ Biorefinery Group, Food Research Department, Faculty of Chemistry Sciences, Autonomous University of Coahuila, Saltillo, Coahuila 25280, Mexico

${ }^{\mathrm{b}}$ Hamburg University of Technology (TUHH), Institute for Thermal Separation Technology, Eißendorfer Straße 38, 21073 Hamburg, Germany

${ }^{\mathrm{c}}$ Beijing Key Laboratory of Lignocellulosic Chemistry, Beijing Forestry University, Beijing 100083, China

${ }^{\mathrm{d}}$ Laboratorio de Futuros en Bioenergía, Unidad Guadalajara de Ingeniería Avanzada, Centro de Investigación y Estudios Avanzados (CINVESTAV), Zapopan, Jalisco, Mexico

${ }^{\mathrm{e}}$ Brazilian Biorenewables National Laboratory (LNBR), Brazilian Center of Research in Energy and Materials (CNPEM), Campinas, São Paulo 13083-100, Brazil

${ }^{\mathrm{f}}$ CEB-Centre of Biological Engineering, University of Minho, Campus Gualtar, 4710-057 Braga, Portugal

${ }^{\mathrm{g}}$ Department of Chemical, Environmental and Materials Engineering, Center for Advanced Studies in Energy and Environment (CEAEMA), University of Jaén, Campus Las

Lagunillas, s/n, Building B3, 23071 Jaén, Spain

${ }^{\mathrm{h}}$ Instituto de Ingeniería Química, Facultad de Ingeniería, Universidad de la República, Montevideo 11300, Uruguay

${ }^{\text {i }}$ Postgraduate Program in Functional and Molecular Biology, Institute of Biology, State University of Campinas, Campinas, São Paulo 13084-970, Brazil

${ }^{\mathrm{j}}$ Center for Lignocellulose Science and Engineering, College of Light Industry and Chemical Engineering, Dalian Polytechnic University, Dalian 116034, China

${ }^{\mathrm{k}}$ Protein Chemistry and Enzyme Technology, DTU Bioengineering, Department of Biotechnology and Biomedicine, Technical University of Denmark, DK-2800 Lyngby,

Denmark

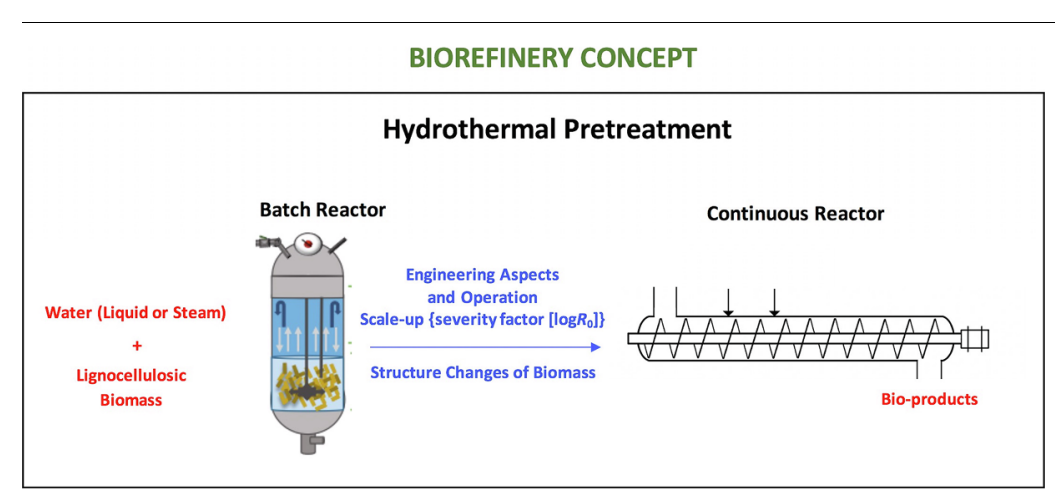

\section{A R T I C L E I N F O}

\section{Keywords:}

Severity parameter

Bioeconomy

Steam explosion

Liquid hot water

Pilot plant

Biomass

\begin{abstract}
A B S T R A C T
Different pretreatments strategies have been developed over the years mainly to enhance enzymatic cellulose degradation. In the new biorefinery era, a more holistic view on pretreatment is required to secure optimal use of the whole biomass. Hydrothermal pretreatment technology is regarded as very promising for lignocellulose biomass fractionation biorefinery and to be implemented at the industrial scale for biorefineries of second generation and circular bioeconomy, since it does not require no chemical inputs other than liquid water or steam and heat. This review focuses on the fundamentals of hydrothermal pretreatment, structure changes of biomass during this pretreatment, multiproduct strategies in terms of biorefinery, reactor technology and
\end{abstract}

\footnotetext{
* Corresponding author.

E-mail address: hector_ruiz_leza@uadec.edu.mx (H.A. Ruiz).
} 


\section{Introduction}

Natural lignocellulosic biomass is essentially resistant to direct enzymatic saccharification. This is due to the tight bonding and close molecular packing of the polymeric constituents cellulose, hemicellulose, and lignin in the cell walls of the biomass as well as the crystalline nature of cellulose. For this reason, in biorefinery processes, a pretreatment step, usually involving treatment of the biomass at increased temperature and pressure (hydrothermal treatment) is introduced for biomass fractionation as first step in a lignocellulosic biorefinery (Sun et al. 2016; Ruiz et al. 2017). These pretreatment processes are mainly intended to enhance the amenability of the cellulose to enzymatic deconstruction, but also induce changes in the plant biomass cell wall structures and alter the biomass composition (Kristensen et al. 2008; Pedersen and Meyer, 2010; Sun et al. 2016). For large scale processes, hydrothermal pretreatment has the advantage that it is more gentle towards the reactor material than acid and alkaline processes, even though some acetate may form during the hydrothermal pretreatment due to deacetylation of xylan at elevated temperature (Pedersen and Meyer, 2010).

Although originally developed mainly for cellulose-to-ethanol processes, these various hydrothermal pretreatment methods are now being adapted to various lignocellulosic biorefinery processes, which is why their differentiated influence on the biomass composition is of critical significance. In addition to introducing more amorphous regions in the cellulose, a hydrothermal pretreatment invariably results in partial fractionation of the biomass due to solubilization of hemicellulose (mainly xylan) and redistribution of lignin (Kristensen et al. 2008; Pedersen et al., 2010; Ruiz et al. 2012a). Although the hydrothermal pretreatment is intended to improve the enzymatic cellulose saccharification, elevated temperature and higher pretreatment severity also forms inhibitors compounds, mainly arising from xylose selfcondensation reactions that form highly potent oligophenolic and bicyclic enzyme inhibitors (Rasmussen et al. 2017a; Rasmussen et al. 2017b). Despite the enhanced formation of inhibitors, overall, at higher severity more hemicellulose is solubilized, and the enzymatic cellulose hydrolysis is generally improved (Yang and Wyman, 2004; Pedersen and Meyer, 2010).

Newer data indicate that surface properties of the pretreated biomass, including the wettability, represented as surface hydrophobicity measured by droplet contact angle measurements, are critical factors affecting enzymatic cellulose biomass saccharification at least for grass biomass lignocellulose (Djajadi et al. 2017). Despite this recent progress the quantitative aspects of the molecular and structural changes occurring in lignocellulosic biomass upon hydrothermal pretreatment are not properly understood. With a new vision to also exploit the lignin more in biorefineries - or even prioritize lignin utilization above cellulose and xylan use the field warrants more research. A deeper understanding of the interplay between the biomass chemistry, biophysical traits, and enzymatic digestibility is a crucial prerequisite for development of new sustainable biorefining processes for the circular economy era. Thus, this review focuses on the most recent works and developments of hydrothermal pretreatment under biorefinery concept for biomass fractionation. The fundamental, structure changes of biomass, multiproduct in terms of biorefinery, reactor technology and engineering aspects from batch to continuous operation, integrated process design using hydrothermal pretreatment are reviewed. A case study for hydrothermal pilot plant in Brazil is also provided.

\section{Fundamental and operation of hydrothermal pretreatment}

Hydrothermal processing (also known as liquid hot water, hydrothermolysis, subcritical water treatment, autohydrolysis) is applied to lignocellulosic materials (LCM) pretreatment include a wide range of operational conditions, e.g., temperature, resident time, particle size, water to solid biomass ratio, among others and it is usually performed at $150-230{ }^{\circ} \mathrm{C}$ for $10-50 \mathrm{~min}$ and pressures (approx. $4.9-20$ bars), because the treatment severity is a compromise between the intention to amend the cellulose to enzymatic attack, avoid production of cellulase inhibitors that may retard the enzymatic efficacy and biomass fractionation (Pedersen and Meyer, 2010; Rasmussen et al., 2014; Aguilar et al., 2018a, Pino et al., 2018).

Depending on temperature and pressure, two types of processes can be differentiated: subcritical operations (below the critical point of water, i.e., $373{ }^{\circ} \mathrm{C}$ and $22.1 \mathrm{MPa}$ ) and supercritical processes beyond this point. Hydrothermal pretreatments should comply with a number of attributes that could be desirable for any advances pretreatment method. As described by Bhutto et al. (2017), it must be cost effective (avoiding for example the need for expensive or very resistant construction materials, catalyst, reagents or neutralization steps); require low energy (for example avoiding the need of using feedstock of small size); and easily to be included in a process integrations and intensification scheme.

The hydrothermal pretreatment with water or steam brings about auto-ionization of water into $\mathrm{H}_{3} \mathrm{O}^{+}$and $\mathrm{OH}^{-}$, which in turn causes the water to act as a catalyst which induces acetate release from xylan and hydrolysis of the glycosidic bonds in the xylan and the subsequent decrease of the $\mathrm{pH}$ of the medium acts as a catalyst for the hydrolysis reactions (Pedersen et al., 2010; Kapu et al., 2016). These events in combination stimulate depolymerization of the hemicellulose (xylan),

Table 1

Comparison of Liquid Hot Water (LHW) and Steam Explosion (SE) pretreatments (Zabed et al. 2016; Bhutto et al. 2017).

\begin{tabular}{|c|c|c|c|}
\hline & Typical operational conditions & Advantages & Challenges \\
\hline LHW & $\begin{array}{l}\text { - } 160-230{ }^{\circ} \mathrm{C} \\
\text { - Pressure to keep liquid water } \\
\text { - Slow pressure release } \\
\text { - } 5-60 \text { min residence time }\end{array}$ & $\begin{array}{l}\text { - Low formation of degradation/inhibiting } \\
\text { products } \\
\text { - No need for neutralization } \\
\text { - Limited corrosion issues } \\
\text { - Results in high hemicellulose sugar recovery } \\
\text { - Increase accessible area }\end{array}$ & $\begin{array}{l}\text { - High amount of solubilized products, but low concentration } \\
\text { - Expensive-energy down-stream processing because of large volumes of water }\end{array}$ \\
\hline SE & $\begin{array}{l}\text { - } 180-240{ }^{\circ} \mathrm{C} \text {, } \\
\text { - }<15 \text { min residence time } \\
\text { - Pressure release suddenly }\end{array}$ & $\begin{array}{l}\text { - Short residence time and low energy } \\
\text { consumption } \\
\text { - No recycling or environmental cost } \\
\text { - Reduction of particle size } \\
\text { - Increase pore volume }\end{array}$ & $\begin{array}{l}\text { - Risk of condensation and precipitation of soluble lignin components making } \\
\text { the biomass less digestible. } \\
\text { - Destruction of a portion of the xylan in hemicellulose } \\
\text { - Possible generation of fermentation inhibitors at higher temperatures } \\
\text { - Reduction of saccharification yields by } 20-25 \% \text { of initial dry matter due to } \\
\text { removal of soluble sugars }\end{array}$ \\
\hline
\end{tabular}


but do not cause significant cellulose hydrolysis (Ruiz et al. 2012b; Ruiz et al. 2013a). In any case, the extent of hemicellulose solubilization and depolymerization are influenced by the operational conditions (temperature and time, mainly), which is expressed as severity factor $\left[\log R_{0}\right]$ (Overend and Chornet, 1987; Chornet and Overend, 2017; Ruiz et al. 2017)- the details of the severity factor and its various forms is discussed in Pedersen and Meyer (2010).

Liquid Hot Water (LHW) and uncatalyzed steam explosion (SE) are the two prominent examples of hydrothermal pretreatment processes for LCM. Both use no other chemicals than water, so they do not present negative effects from an environmental point of view. The removal of hemicelluloses is considered the main reason for the changes detected in the SE-pretreated materials, resulting in an improved accessibility to cellulolytic enzymes, while this is attributed to structural and chemical changes in the lignin fraction in the case of LHW pretreatment. Comparing LHW and steam explosion SE pretreatments, the sudden release of the high pressure has been reported to be responsible of the increase of accessibility to the cellulose backbone and thus the improvement of enzymatic hydrolysis. Results obtained applying LHW or SE may differ based on the LCM and operational conditions and it is not clear whether or not the sudden release of pressure in the case of SE produces a beneficial effect (Pielhop et al. 2016). SE combines mechanical effects (steam causes a mechanical fracture on fiber when it is released following pressure drop) with the chemical action derived from the hydrolysis of acetyl groups. Table 1 shows the comparison between LHW and SE pretreatments in terms of operational conditions and process advantages.

\subsection{Structure changes of cellulose during hydrothermal pretreatment}

The structure of cellulose, like crystallinity and degree of polymerization (DP), changes slightly during most actual hydrothermal pretreatment process. Sun et al. (2015a) evaluated the effect of hydrothermal pretreatment at $110-210{ }^{\circ} \mathrm{C}$ for $0.5-2.0 \mathrm{~h}$ on the saccharification ratio of sweet sorghum stem. It was found that the crystallinity of the substrates increased to some extent. Similarly, Xiao et al. (2014) pretreated bamboo with hot water at $140-200{ }^{\circ} \mathrm{C}$ for $10-120 \mathrm{~min}$ to improve the enzymatic hydrolysis of the pretreated substrates. After the pretreatment, the cellulose crystallinity elevated slightly with the increasing pretreatment severity, but the crystalline cellulose was not remarkably affected by the hydrothermal pretreatment. The increased crystallinity is mostly achieved by the removal of amorphous components (mainly hemicelluloses and lignin).

The degradation of cellulose at relatively high hydrothermal pretreatment severity has also been explored to understand its degradation behavior in deep (Pino et al., 2019). Normally, the crystalline cellulose is more difficult to be hydrolyzed than the amorphous cellulose. Yu and Wu, (2010) reported that the glycosidic bonds of the amorphous cellulose started breaking slowly from $150{ }^{\circ} \mathrm{C}$, while the cleavage of the glycosidic bonds in the crystalline cellulose occurred from $180^{\circ} \mathrm{C}$. Thus, the removal of amorphous cellulose at relatively severe hydrothermal pretreatment conditions can improve the crystallinity of cellulose to some degree. Li et al. (2017) examined the effect of hydrothermal pretreatment severity factors $\left[\log R_{0}\right]$ between 3.6 and 4.2 on the chemical-structural alteration of fast-grown poplar (Populus trichocarpa). The cellulose crystallinity increased $6-9 \%$, while its degree of polymerization decreased 35-65\% after the pretreatment. Ma et al. (2013) investigated the degradation behavior of cellulose at $150-180{ }^{\circ} \mathrm{C}$ with different duration (20-240 min). A slightly higher DP than raw material was observed at low temperature pretreatment because of the dissolution of reactive cellulose with low DP. Treatment at higher temperature $\left(\geq 170{ }^{\circ} \mathrm{C}\right.$ ) caused severe cleavage of cellulose and therefore gave rise to low DP with better solubility. Normally, cellulose with low DP is beneficial to increase the number of reducing ends of cellulose chain and make cellulose more reactive to the enzymes, thus improving its enzymatic hydrolysis efficiency.

\subsection{Structure changes of hemicelluloses during hydrothermal pretreatment}

Among the main components of biomass, hemicelluloses are the most thermo-chemically sensitive (Agbor et al., 2011). Hemicelluloses within plant cell walls are thought to 'coat' cellulose-fibrils and the removal of hemicelluloses can significantly increase the accessibility of enzyme to cellulose. Generally, with the increase of the hydrothermal pretreatment severity $\left[\log R_{0}\right]$, the removal of hemicelluloses increases constantly, and most hemicelluloses can be dissolved into the liquor phase at $160-180^{\circ} \mathrm{C}$. Recently, several studies have explored the effects of hydrothermal pretreatment on the removal of hemicelluloses and the chemical composition of the hydrolysate (Sun et al., 2015b; Wang et al., 2016; Chen et al., 2018). Chen et al. (2018) investigated the degradation behavior of hemicelluloses from wheat straw at $120-200{ }^{\circ} \mathrm{C}$ in the process of hydrothermal pretreatment and reported that the hemicelluloses content gradually decreased from 27.06 to $0.74 \%$ as temperature increased. In the hydrolysate (liquid phase), the concentrations of xylose, xylooligosaccharides (XOS) and glucooligosaccharides increased dramatically from $0.34,2.49$ and 3.17 to $6.04,61.69$ and $8.16 \mathrm{~g} / \mathrm{kg}$ wheat straw with the rise of temperature from 120 to $180^{\circ} \mathrm{C}$, and then decreased to $1.87,1.27$ and $1.08 \mathrm{~g} / \mathrm{kg}$ wheat straw as the temperature further rose to $200{ }^{\circ} \mathrm{C}$, respectively. After the hydrothermal pretreatment, a small amount of hemicelluloses still remain in the lignocellulosic residues (Sun et al., 2014a; Li et al., 2017). Accompanying with the solubilization and depolymerization of hemicelluloses, the molecular weights of the remaining hemicelluloses exhibited significant reduction $(60-75 \%)$ after the fast-grown poplar was hydrothermally pretreated at different severity factors $\left(\left[\log R_{0}\right]=3.6-4.2\right.$ ) (Li et al., 2017).

\subsection{Structure changes of lignin during hydrothermal pretreatment}

Lignin is considered as the most recalcitrant component of the major plant cell wall biopolymers. At the typically used hydrothermal pretreatment temperatures, the lignin turns into a fluid-like state (depending on its glass transition temperature $(\mathrm{Tg})$ ), and the pretreatment heating and subsequent cooling will cause the lignin to relocate within and on the cell wall material and simultaneously, a small amount of lignin will dissolve in the hot water. Droplets of recondensed lignin thus redeposit on the surface of the material after pretreatment (Donohoe et al. 2008). This relocation improves accessibility of the cellulases to the cellulose in the biomass as a larger cellulose area is exposed upon lignin removal and re-deposition. A few reports suggest that the lignin droplets themselves may sterically retard the cellulolytic enzymes attack or partially or temporarily adsorb some of the cellulase enzyme protein molecules (Selig et al. 2007; Li et al. 2014). Therefore, only a small amount of lignin is dissolved in the hydrolysate for most hydrothermal pretreatment process, and the removal of lignin is related to the pretreatment severity (Pu et al., 2013). Sun et al. (2014b) observed that the pretreatment at $100-180{ }^{\circ} \mathrm{C}$ resulted in $0.9-13.2 \%$ lignin removal of thermo-mechanical fiber from Eucalyptus urophylla. Likewise, a decrease of $12 \%$ lignin from corn stover after the pretreatment at $200{ }^{\circ} \mathrm{C}$ for $20 \mathrm{~min}$ was also reported in a previous literature (Liu and Wyman, 2005). Therefore, a relatively comparable or higher lignin and cellulose content could be detected in the hydrothermally pretreated biomass because of the extensive removal of hemicelluloses and/or the formation of pseudo-lignin at much higher hydrothermal pretreatment severity (Xiao et al., 2013; Chen et al., 2018).

During the hydrothermal pretreatment, the dominant reactions for lignin are the cleavage of $\beta-O-4$ linkages and acid-catalyzed condensation (Pu et al., 2013). Hydrothermal pretreatment with mild severity usually causes a decline in molecular weight of lignin due to the cleavage of $\beta-0-4$ linkages. A decrease of $8 \%$ in lignin molecular weight was detected when Tamarix ramosissiva stalks were subjected to hydrothermal pretreatment at $170{ }^{\circ} \mathrm{C}$ for $2 \mathrm{~h}$ (Xiao et al., 2012). A decrease of $46-85 \%$ for lignin molecular weight in the hydrothermally 
pretreated poplar at $150-200{ }^{\circ} \mathrm{C}$ was also observed in a previous work (Samuel et al., 2013), suggesting that depolymerization was the dominant reaction rather than recondensation. However, the broken lignin fragments may be condensed under much severe pretreatment conditions, resulting in an increase in the molecular weight of lignin (Pu et al., 2013). During the hydrothermal pretreatment process, lignin or its dissolved fragments may coalesce and migrate within and out of the cell wall and redeposit on the surface of the lignocellulosic residues (Donohoe et al., 2008). In the process of the following enzymatic hydrolysis, the redeposited lignin hinders the accessibility of cellulase to cellulose via physical barrier and nonspecific adsorption of cellulase on the lignin. Thus, the pseudo-lignin and re-deposition of the formed lignin droplets significantly impact the cellulose hydrolysis (Selig et al., 2007; Ruiz et al., 2011a; Ruiz et al., 2012a; Hu et al., 2012; Pino et al., 2019).

\subsection{Distribution changes on plant cell walls during hydrothermal pretreatment}

Besides the content and structure changes of the main components in lignocellulosic biomass, various technologies have been developed to explore the microscopic distribution changes of these major components during the hydrothermal pretreatment. The study on the distribution changes of these main components is not only beneficial to understand the dissolution mechanism of different components from the cell walls, but also to design and optimize pretreatment strategies. Therefore, the changes in the distributions of the main cell wall components during hydrothermal pretreatment are discussed in this section.

Nowadays, a novel glycome profiling technique has been developed to monitor structural/extractability changes in untreated and hydrothermally-pretreated biomass. Results from this technology demonstrated that during the hydrothermal pretreatment pectins and arabinogalactans were firstly dissolved, followed by the obvious dissolution of xylans and xyloglucans (DeMartini et al., 2011). Ma et al. (2014) investigated the topochemical changes of poplar cell walls before and after the hydrothermal pretreatment $\left(170{ }^{\circ} \mathrm{C}, 0-40 \mathrm{~min}\right)$ by confocal Raman microscopy (CRM). They found that as the pretreatment time prolonged, hemicelluloses and lignin were gradually dissolved from the cell was, resulting in the exposure of cellulose. Additionally, the microdistribution of xylan in poplar fiber cell walls during the hydrothermal pretreatment was also studied by Ma et al. (2015) using transmission electron microscopy (TEM) in combination with immunogold labeling. It was reported that the lignin-free xylan was initially removed from the S2 layer, then the S1 layer, and then the xylan covalently bounded with lignin was removed from the S2 layer with the removal of lignin. However, the xylan tightly bound to the surface of cellulose microfibrils was hardly removed.

For a better understanding of biomass surface changes during the hydrothermal pretreatment, especially the topochemical variation of lignin distribution, time-of-flight secondary ion mass spectrometry (ToF-SIMS) combined scanning electron microscope (SEM) has been used to provide chemical information directly from the surface of biomass without sample treatment such as matrix application or isotopic labeling (Jung et al., 2018). The topochemical variation of lignin distribution during hydrothermal flowthrough pretreatment at $160{ }^{\circ} \mathrm{C}$ for 10-150 min was explored by Jung et al. (2018). Their results showed that more lignin was found on the surface of biomass at the early stage, while the lignin mainly observed at the cell corners was gradually reduced by extended pretreatment time. Additionally, due to the autofluorescence properties of lignin, confocal laser scanning microscopy (CLSM) is also used to detect the location and relative concentration of lignin. When Eucalyptus globulus was subjected to hydrothermal pretreatment, a substantial amount of fluorescent droplets covered the fiber surfaces, suggesting the migration and re-localization of lignin, and the phenomenon was increased as the pretreatment severity increased (Arévalo et al., 2017). Meanwhile, atomic force microscopy (AFM) showed that the pretreated surfaces appeared roughness and coalescence droplets and this phenomenon was more obvious in the samples treated at more severe conditions (Arévalo et al., 2017). The spatial distribution of lignin, hydroxycinnamic acids (HCA), and cellulose in the cell walls of four energy crops before and after the hydrothermal treatment were measured by CRM at subcellular level In situ (Li et al., 2018). It was investigated that after the pretreatment, the concentrations of lignin and HCA in the same cell types were declined

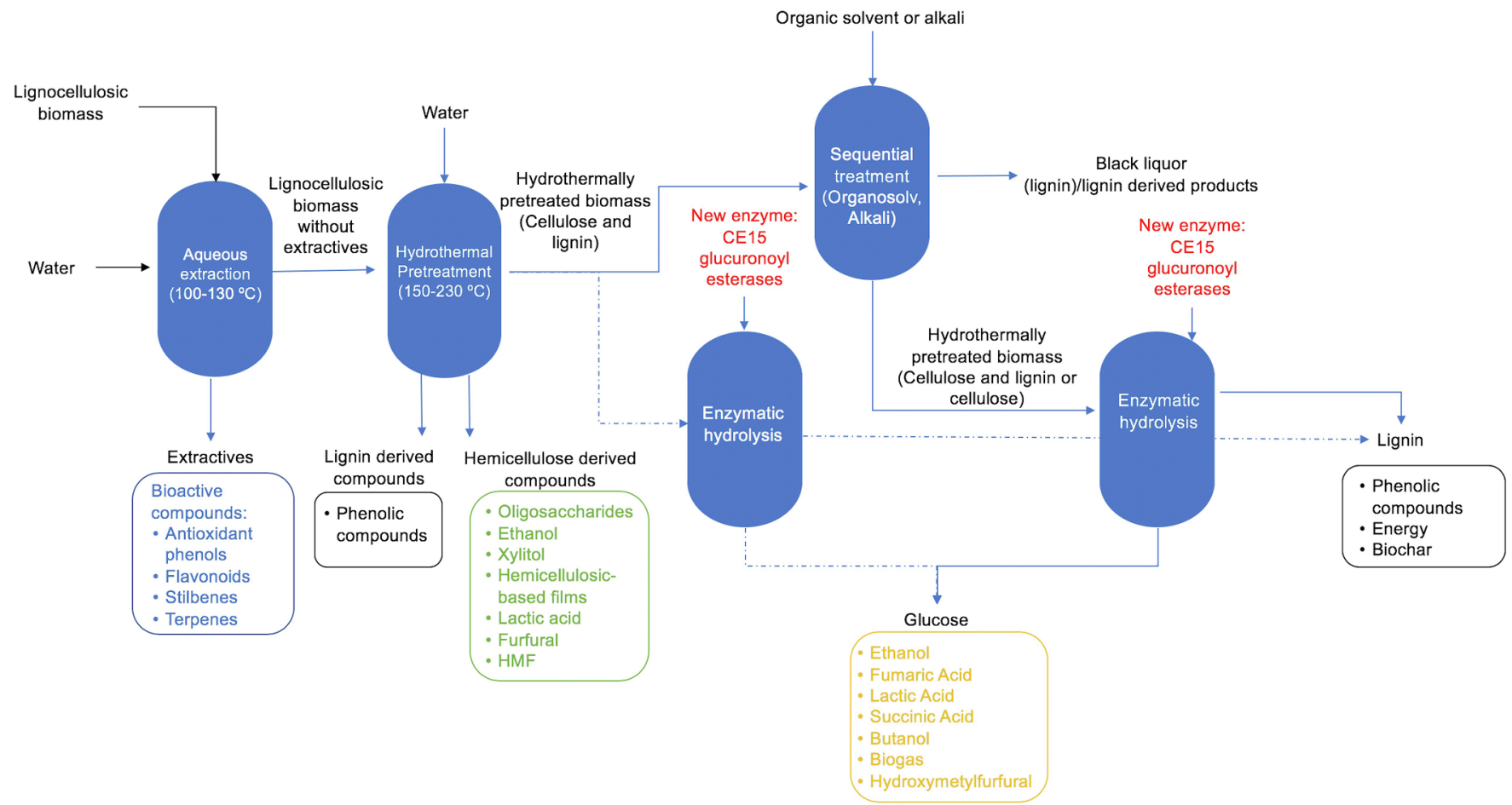

Fig. 1. Biorefinery scheme for lignocellulosic biomass for hydrothermal pretreatment in the production of high added products and biofuels. 
as compared to the corresponding raw crops. The removal of lignin mainly occurred in the sclerenchyma fiber (Sf), especially in the secondary wall (SW) layers, as compared with that in the parenchyma (Par). By contrast, cellulose concentrations were increased in the pretreated crops for the same cell types, especially at the Sf, indicating the increased exposure of cellulose. Holopainen-Mantila et al. (2013) also reported that the cellulose concentration increased after pretreatment by the detecting the increment of cellulose Calcofluor staining in the cell wall level, which was due to removal of other cell wall components, thus leading to an increase in the relative amount of cellulose and further improving the subsequent enzymatic hydrolysis.

\section{Multiproduct biorefinery using hydrothermal pretreatment}

The development and feasibility of a lignocellulosic biorefinery depends on the pretreatment selected for the biomass processing since the recalcitrant structure of lignocellulosic biomass is the first barrier for a marketing of its main fractions (cellulose, hemicellulose and lignin) in terms of biorefinery concept (Garrote et al. 1999; Gullón et al., 2012; Ruiz et al. 2013a; Ruiz et al. 2013b; Ruiz et al. 2017).

The last few decades, great efforts have been devoted looking for a cost-efficient pretreatment to produce second generation biofuels or lignocellulosic biofuels for their large-scale commercialization. In this sense, the hydrothermal treatment has been gaining importance. Hydrothermal pretreatment is one of the most referenced treatments used to increase the enzymatic accessibility towards cellulose (Romaní et al. 2010; Ruiz et al. 2013a). The authors approached important factors influencing enzymatic saccharification of hydrothermally pretreated biomass, namely: soluble degradation compounds derived from pretreatment (such as furfural, hydroxymethylfurfural, acetic acid and phenolic compounds), the effect of remained lignin after hydrothermal pretreatment, structural characteristics (as described above), feedback inhibition of cellobiose and the importance to operate at high solid loadings to attain a final ethanol titre, reducing operational cost of distillation (Romaní et al., 2012; Zhuang et al., 2016; Pino et al., 2019). Recently, a horizontal bioreactor was designed to carried out the enzymatic saccharification of hydrothermally pretreated $\left(194{ }^{\circ} \mathrm{C}\right.$ for $30 \mathrm{~min}$ ) agave bagasse at $25 \% \mathrm{w} / \mathrm{v}$, achieving $195.6 \mathrm{~g} / \mathrm{L}$ of glucose with a cellulose conversion of $98 \%$ (Pino et al., 2019).

Hydrothermal pre-treatment (aqueous extraction) at milder temperatures (as for example $130{ }^{\circ} \mathrm{C}$ ) has been reported as a sustainable process for the extraction of non-structural components as extractives (rich in bioactive compounds such as antioxidant phenols, stilbenes, flavonoids and terpenes) (Conde et al., 2014). Despite the low concentration of these bioactive compounds in the lignocellulosic extractives, they are considered high value compounds with application in pharmaceutical, nutraceutical and cosmetic industries, which could improve the economic profitability of a lignocellulosic biorefinery. In this regard, vine pruning residues were submitted to water extraction at $120{ }^{\circ} \mathrm{C}$ for $40 \mathrm{~min}$ using microwave-assisted technology to obtain total phenolic compounds ( $2.4 \mathrm{~g}$ gallic acid equivalent/100 g raw material), composed mainly by flavonoids, with antioxidant activity (Jesus et al., 2019). After this, the extractive-free lignocellulosic biomass could be further processed to separate its main structural components (Fig. 1). By using the classic hydrothermal pretreatment as a fractionation technology for obtaining: 1) A hemicellulose rich stream - in most cases this fraction will mainly consist of xylo-oligosaccharides from which a fan of value-added products can be obtained (Fig. 1); 2) A cellulosehydrolysate stream resulting from proper enzymatic degradation of the cellulose in the biomass (Fig. 1); 3) A lignin fraction (Fig. 1). Combined with new enzyme discoveries, such as CE15 glucuronoyl esterases able to catalyze cleavage of lignin-carbohydrate complexes in biomass (d'Errico et al., 2016; Mosbech et al. 2018) it may be possible to improve the resource use further by e.g. polishing the lignin enzymatically to allow new uses of lignin as well, in total generating a sequential biorefinery processing scheme for lignocellulosic biomass (Fig. 1).

Several feedstocks (such as Eucalyptus wood, wheat straw, corn cob) have been submitted to hydrothermal pretreatment under non-isothermal and isothermal conditions to obtain xylooligosaccharides (XOS) (Gullón et al., 2010; Ruiz et al., 2011b; Romaní et al., 2011; Michelin et al., 2018). These XOS are considered functional foods with interesting prebiotic features that have health benefits (Gullón et al., 2010). Products obtained from hemicellulose, cellulose and lignin using hydrothermal processing for the fractionation of lignocellulosic biomass in terms of biorefinery are summarized in Table 2 . Recently, a 50\% XOS yield was obtained from hydrothermal pretreatment of sugarcane bagasse at $200{ }^{\circ} \mathrm{C}$ for $10 \mathrm{~min}$ (Zhang et al., 2018). Under an isothermal regime $\left(180{ }^{\circ} \mathrm{C}\right.$ for $\left.20 \mathrm{~min}\left[\log R_{0}\right]=3.85\right), 15.31 \mathrm{~g} / \mathrm{L}$ of XOS were obtained from hydrothermal pretreatment of agave bagasse (Aguilar et al., 2018b). Hydrothermal pretreatment followed by an acid posthydrolysis has also been used to obtain monosaccharides as xylose for the production of xylitol, lactic acid and ethanol by fermentation processes (Cubas-Cano et al., 2019; Cunha et al., 2019). Furan compounds (furfural and hydroxymethylfurfural) are other important building blocks (included by U.E. Energy Department in the top value-added chemicals) that can be obtained from hemicellulose by

Table 2

Products obtained from hemicellulose, cellulose and lignin using hydrothermal processing in terms of biorefinery.

\begin{tabular}{|c|c|c|c|}
\hline Raw material & Hydrothermal pretreatments conditions & Manufacturing products & References \\
\hline \multicolumn{4}{|c|}{ - Hemicellulose derived compounds } \\
\hline Corn cob & {$\left[\log R_{0}\right]=4.42$} & $22 \mathrm{~g} / \mathrm{L}$ of XOS & (Michelin et al., 2018) \\
\hline Agave bagasse & $180^{\circ} \mathrm{C}$ for $20 \mathrm{~min} .\left[\log R_{0}\right]=3.85$ & $15.3 \mathrm{~g} / \mathrm{L}$ of XOS & (Aguilar et al., 2018b) \\
\hline Wheat straw & $180{ }^{\circ} \mathrm{C}$ for $4 \mathrm{~min}$. & $71 \%$ of Lactic acid yield & (Cubas-Cano et al., 2019) \\
\hline Miscanthus giganteus & $\begin{array}{l}211{ }^{\circ} \mathrm{C} \text { non-isothermal regime followed by acid treatment in biphasic } \\
\text { system }\end{array}$ & $78 \%$ of furfural molar yield & (Rivas et al., 2019) \\
\hline \multicolumn{4}{|c|}{ - Cellulose derived products } \\
\hline Agave bagasse & $\begin{array}{l}180{ }^{\circ} \mathrm{C} \text { for } 20 \mathrm{~min} .\left(\left[\log R_{0}\right]=4.11 \text { ) followed by pre-saccharification and }\right. \\
\text { simultaneous saccharification and fermentation }\end{array}$ & $52.02 \mathrm{~g} / \mathrm{L}$ of ethanol & (Aguilar et al., 2018b) \\
\hline Eucalyptus sawdust & $\begin{array}{l}180{ }^{\circ} \mathrm{C} \text { for } 45 \mathrm{~min} \text {. followed by enzymatic hydrolysis and isopropanol- } \\
\text { butanol-ethanol }\end{array}$ & $0.15 \mathrm{~g}$ butanol/g sugars & (Cebreiros et al., 2019) \\
\hline Coffee silverskin & $\begin{array}{l}170{ }^{\circ} \mathrm{C} \text { for } 20 \text { min. followed by enzymatic hydrolysis and acetone-butanol- } \\
\text { ethanol fermentation }\end{array}$ & $0.269 \mathrm{~g}$ of butanol/g sugars & $\begin{array}{l}\text { (Hijosa-Valsero et al., } \\
\text { 2018) }\end{array}$ \\
\hline \multicolumn{4}{|c|}{ - Lignin derived compounds } \\
\hline Vine shoots & $215{ }^{\circ} \mathrm{C}$ in non-isothermal regime followed by ethyl acetate extraction & Phenolic compounds & (Gullón et al., 2017) \\
\hline Grape stalks & $180^{\circ} \mathrm{C}$ for $30 \mathrm{~min}$. & $\begin{array}{l}2 \% \text { total phenolic compounds recovered of } \\
\text { g raw material }\end{array}$ & (Amendola et al., 2012) \\
\hline European biomass residues & $\begin{array}{l}190{ }^{\circ} \mathrm{C} \text { for } 15 \mathrm{~min} \text {. followed by enzymatic hydrolysis and hydrothermal } \\
\text { carbonization }\end{array}$ & Biochars & (Wikberg et al., 2017) \\
\hline
\end{tabular}


depolymerization of pentoses and hexoses. Hydrolysate obtained from hydrothermal treatment (under non-isothermal regime at $196{ }^{\circ} \mathrm{C}$ ) of Eucalyptus wood was also used for furfural production (Peleteiro et al., 2016).

Non-saccharides compounds (as lignin-derived phenolic compounds) are present in liquid phase from hydrothermal pretreatments. These phenolics (such as benzoic acid, cinnamic acids and flavonoids) are value-added compounds due to interesting biological activities, including: antioxidant, cardioprotective, neuroprotective, anticancer, anti-inflammation, antimicrobial and antiaging) (Gullón et al., 2017). Amendola et al. (2012) proposed the combination of two environmental friendly processes for the fractionation of grape stalks and they recovered $2 \%$ of total phenolics from the hydrolysate obtained by hydrothermal treatment $\left(180{ }^{\circ} \mathrm{C}\right.$ for $\left.30 \mathrm{~min}\right)$. Recently, the antioxidant and antibacterial effects of phenolic compounds present in autohydrolysis liquor of vine shoots were evaluated (Gullón et al., 2017).

Besides the ethanol production from hydrothermal treated lignocellulosic biomass, this process had been used for the production of other biofuels such as butanol (Cebreiros et al., 2019). Recently, autohydrolyzed coffee silverskin for biobutanol production by acetonebutanol-ethanol fermentation using a Clostridium beijerinckii CECT 508 (Hijosa-Valsero et al., 2018). Overall, the hydrothermal pretreatment allows to be used alone or combined with other biotechnological processes (organosolv or alkali) to obtain a wide spectrum of manufacturing products (such as biofuels, chemicals and food additives) (Chen et al., 2016). Moreover, the use of water as only reaction media enables the downstream processing.

\section{Reactor technology and engineering aspects of hydrothermal pretreatment}

\subsection{Batch reactor Technology: Liquid hot water and steam explosion}

There are different configurations reactors and technologies for hydrothermal pretreatment applied to the fractionation of the main components of lignocellulosic biomass. In general terms, the most common operation mode is the batch configuration reactor at different scale levels from bench $(0.025-3 \mathrm{~L})$ and pilot scale $(15-350 \mathrm{~L})$. For LHW batch reactor the lignocellulosic biomass (solid particles) and liquid water are mixed and loaded together into the reactor, heat-up and left to react during a certain time of residence. However, this operating condition depends on whether it is an isothermal or non-isothermal regimen. Easiness of operation, non-expensive design, easy scale-up, possibility of fast heat transfer (if direct steaming as steam explosion batch reactor), control system and operation at several Liquid/biomass ratios are mentioned as its main advantages; while large heat consumptions, and challenging heat recovery are the disadvantages. According to Ruiz et al. (2013a) and Ruiz et al. (2017) reported that there are different heat transfer phenomena: conduction, convection or radiation, depending on the heating source used in the rector as electrical heating, microwave radiation, steam injection, thermal oil jacket, oil bath and fluidized sand baths (Ruiz et al 2011a; Ruiz et al. 2011b). Aguilar-Reynosa et al. (2017) studied and compared two heating forms as conduction-convection and radiation (microwave) in the production ethanol production using corn residues as raw material, obtaining $87.33 \%$ (and $92 \%$ of conversion ethanol yield for

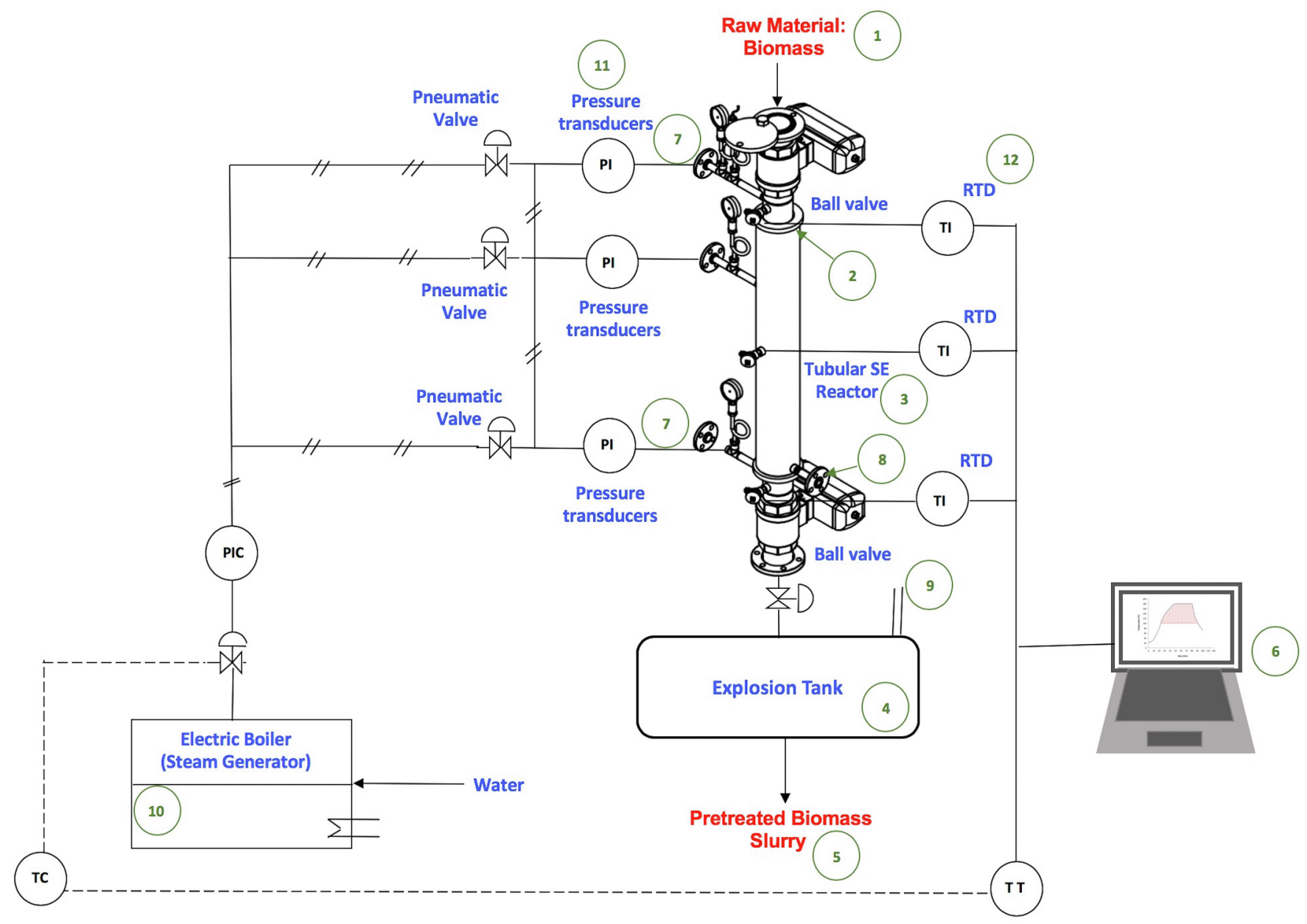

Fig. 2. Schematic diagram of the tubular SE batch reactor and instrumentation in Biorefinery Pilot Plant at Autonomous University of Coahuila for biomass fractionation. 
conduction-convection and microwave processing, respectively. Gonçalves et al. (2015) produced xylooligosaccharides (16.52 g/L) from mature coconut shell at $\left(200{ }^{\circ} \mathrm{C} / 50 \mathrm{~min}\right)$ using an oil bath as heating source of LHW. In regarding to kinetics and mass transfer of hemicellulose solubilization and depolymerization during LWH (autohydrolysis) in batch mode, Mittal et al. (2009) proposed a mathematical model of first order kinetics that can be correlate the deacetylation of xylan, xylooligomers and xylose in the liquid phase.

On the other hand, the severity parameter $\left[\log R_{0}\right]$ can be considered as a strategy of scaling-up process in batch mode operation from benchpilot-demonstration and commercial-scale reactor (Overend and Chornet, 1987; Chornet and Overend, 2017; Ruiz et al. 2017; Zanuso et al. 2017; Lara-Flores et al. 2018; Conrad et al. 2019), since the severity factor can relate the temperature of operation (considering heating and cooling period), and residence time on the biomass. In a recent work, Aguilar et al. (2018b) reported the scale-up of hydrothermal pretreatment for agave biomass using the severity factor $\left(\left[\log R_{0}\right]=4.11\right)$, in order to obtain a pretreated solid in cellulose. They scaled-up the hydrothermal pretreatment from 0.125 to $0.750 \mathrm{~L}$. Also, there are other important scaling-up strategies for pretreatment as engineering heuristics, similarity criteria and dimensional analysis. Rossner and Parra, (2017) described the pilot plant for the conversion of lignocellulosic biomass (wood) into biofuels and the hydrothermal batch reactor with a capacity of $88 \mathrm{~L} \mathrm{(10-14} \mathrm{kg} \mathrm{of} \mathrm{dry} \mathrm{wood),} \mathrm{installed}$ at Universidad de Concepción in Chile. They reported that the hydrothermal pretreatment is a good process for eucalyptus wood compared with organosolv pretreatment using the same reactor in terms of sugars recovery, the heating source for this pretreatment is using a $100-\mathrm{kW}$ electric heater.

Moreover, the SE in batch mode configuration has been reviewed by Jacquet et al. (2015), Chen and Sui (2017), Lara-Flores et al. (2018) and used at the pilot and full-scale plant. In this process the lignocellulosic biomass is treated and fractionated with saturated steam at $150-230{ }^{\circ} \mathrm{C}$ (similar at LHW) and short residence times (seconds to few minutes). The main process effects on biomass are the high pressure into the reactor, residence time and the rapid depressurization in the reactor. Jacquet and Richel (2017) adapted of severity factor to temperature and $\mathrm{pH}$ during SE, they reported that the severity parameter should include the temperature and $\mathrm{pH}$ (related to the biomass reactivity) during the SE processing.

In our biorefinery research group (www.biorefinerygroup.com), the design and operation of a pilot-scale tubular steam explosion batch reactor has been developed for the fractionation of biomass in terms of biorefinery (Singh et al. 2019). The design of the SE reactor was developed in three main stages: 1) The conceptual engineering design consisted mainly on the initial study of feasibility and the definition of the bioreactor basic requirements; 2) Basic engineering design consisted on the definition of the definitive requirements of the reactor, including all the basic specifications, such as, needed components, operational strategies, technical and even economical evaluation of the equipment; 3 ) the detailed engineering design consisted on the verification of the reactor performance to confirm compliance with the purpose of its design. The tubular SE pilot reactor includes: 1) biomass loading, 2) pre-heating jacket, 3) tubular SE batch reactor, 4) explosion tank, 5) pretreated slurry [cellulignin and hemicellulose], 6) computer control PLC and data acquisition, 7) steam input, 8) purge valve, 9) exhaust pipe, (10) electric steam boiler, (11) pressure transducer, (12) RTD (resistance temperature detectors). Fig. 2 shows the schematic diagram of the tubular SE batch reactor and instrumentation in Biorefinery Pilot Plant at Autonomous University of Coahuila for biomass fractionation.

\subsection{Semi-Continuous reactor technology: Fixed-bed reactor and Flow- Through reactor}

In the fixed-bed reactor (FBR), the biomass is retained in the reactor, while hot water is pumped through. This method is called flow- through (FT) or semi-continuous pretreatment. The FBR allows a fluid residence time shorter than the extraction time. The hot water induces the autohydrolysis process to take place and extracts the soluble but thermally labile sugar products. The hemicellulose-derived sugars leave the reaction zone continuously. Therefore, degradation reactions are reduced.

A large variety of materials have been tested successfully using the FBR including softwood and hardwood (Cabeza et al., 2016), straws (Liu and Wyman, 2003; Ingram et al., 2009), and other lignocellulose biomasses from agro- and food industry (Pronyk and Mazza, 2010; Torres-Mayanga et al., 2019). The particle forms tested include cut straws, wood chips, sawdust, and straw pellets. The strengths of this reactor type are the high yield of hemicellulose-derived sugars and the high enzymatic digestibility of the pretreated solids. The latter is due to almost complete hemicellulose solubilization, high lignin particle removal by fluid drag (Yang and Wyman, 2004; Reynolds and Smirnova, 2018) and avoidance of condensation reactions (Cocero et al., 2018). The main drawbacks are the substantial water consumption, limited reactor loading due to low bulk density, bed-compaction, and large size of reactors (Archambault-Léger and Lynd, 2014; Steinbach et al., 2017).

A flow-through pretreatment without the addition of chemicals was first patented in 1968 by Ortwin Bobleter and Gerhard Pape (Bobleter and Pape, 1968). In the second half of that century, various materials were fractionated in laboratory-scale FBR reactors (Mok and Antal, 1992). In 2005 Liu and Wyman, (2005) proposed a partial flow operation reducing the water consumption to a liquid-to-solid mass ratio of five (L/S = 5) (Liu and Wyman, 2005). A one-liter scale reactor was first operated by Ingram et al. (2009). The research group at the Hamburg University of Technology proposed the use of a cartridge for fast loading of a $3 \mathrm{~L}$ and $40 \mathrm{~L}$ FBR (Reynolds et al., 2015; Reynolds et al., 2019). In 2014 Kilpeläinen et al. (2014) presented results of a scale-up to a $300 \mathrm{~L}$ reactor, which is the largest size published today (Kilpeläinen et al., 2014).

\subsubsection{Mode of operation}

The hot water flow profile, in most cases, is constant but can also be stepwise, recirculated, or partially recirculated (Liu and Wyman, 2005; Schmidt et al., 2018). An upward flow in a vertical setup is most common.

A process pressure above the water vapor pressure is applied, to ensure a liquid state of the fluid. There are several techniques to introduce pressure to the reactor: (1) cold water is pumped through; the air is replaced. The pressure is increased using the outlet valve; then the inlet water stream is heated to the desired temperature. (2) A gas, e.g. nitrogen, is introduced to the reactor to increase the pressure; then hot water is pumped into the reactor. Air and gas are pressed out at the top. (3) Hot water is pumped into the unpressurized reactor, which will evaporate to preheat the biomass and replace the air. The outlet valve is closed, and the pressure set after the fluid has left the reactor.

The hot outlet steam, now called hydrolysate, is cooled below $100{ }^{\circ} \mathrm{C}$ before the pressure is released. A common approach to stop the extraction is to cool the reactor by pumping cold water into it before releasing the pressure. A method for a fast depressurization is to stop the water flow and release the pressure in a hot state. The forming steam forces the remaining water out. The thermal energy of the hot effluent can be used to preheat the inlet water. Alternatively, it is proposed to be utilized in the evaporation stage, reducing the energy demand here (Schmidt et al., 2018). Heat is introduced to the biomass by a heated jacket, pre-steaming, and the liquid hot water flow. While small research reactors are heated with electrical jackets, a surrounding oven or fluidized sand bath, larger reactors make use of a heating fluid in the jacket. Pre-steaming leads to fast and homogeneous heat up to a temperature slightly below the processing temperature. The heat introduction by hot water is inhomogeneous and takes longer than the fluid residence time. The heat transfer to the solids cools the hot water. The biomass temperature near the entrance increases most rapidly. 
Regarding the solids treatment, the FBR is operated in batch mode. Therefore, the biomass needs to be loaded to the reactor and unloaded after the treatment. Three methods can be distinguished. (1) In small research reactors $(<1 \mathrm{~L})$ the reactors are made of a pipe attached to an inlet and an outlet filter at each end. Before and after the experiment, the reactor is assembled and disassembled, respectively. (2) For larger reactors $(3-40 \mathrm{~L})$ a cartridge is used for loading. It is a thin-walled pipe with detachable filters, which can be used as a basket. The cartridge is filled with biomass, closed and lifted into the pressure vessel. A cable winch or crane is used to lift the cartridge. This is necessary due to the weight, especially when filled with water-soaked biomass. (3) A stationary reactor possesses removable metal filters. The bottom filter is centrally attached to a metal rod, which remains inside the reactor during treatment. To remove the biomass a ring is attached to the rod and hooked to a crane. The filter and biomass-bed are lifted as a whole. If the bed is brittle, it is lifted slowly while being manually shoveled to another vessel. For large-scale reactors, it is proposing the use of screw feeders to load and unload fixed-bed reactors.

The most critical parameters affecting the FBR performance are the solid and liquid residence times, the initial biomass loading, the particle type and size, the length to diameter ratio as well as the fluid velocity and temperature. The hemicellulose removal usually reaches $90 \%$ or more. The hemicellulose recovery in the hydrolysate is close to $100 \%$ for many reported cases that have a small reactor size in common (Mok and Antal, 1992; Liu and Wyman, 2003; Ingram et al., 2009). Some show a high water consumption (L/S = 45-390) (Mok and Antal, 1992; Liu and Wyman, 2003; Pronyk and Mazza, 2010; Cabeza et al., 2016). Experiments with reactor sizes between 3 and $300 \mathrm{~L}$ reported a hemicellulose recovery in the range $47-77 \%$ (Kilpeläinen et al., 2014; Reynolds et al., 2015). Kilpeläinen et al. (2014) achieved the $77 \%$ recovery in a $300 \mathrm{~L}$ FBR using spruce sawdust, a liquid-to-solid ratio of L/ $S=22$, and a liquid residence time of $12 \mathrm{~min}$.

Limitations of the fixed-bed reactors are the substantial water consumption and the challenging loading and unloading techniques as discussed earlier. The axial dispersion and the initial bed density require consideration. The axial dispersion and the residence time distribution are essential characteristics to evaluate the heat transfer and the yields of the sugars and degradation products. A significant deviation from the ideal plug flow was found in a $3 \mathrm{~L} \mathrm{FBR}$ operated with pelleted wheat straw (Reynolds et al., 2015). In the same work, a proportional dependency of the axial dispersion coefficient to the fluid velocity was determined. A densely packed reactor is, on the one hand, beneficial for the reactor productivity, on the other hand, it increases the pressure drop. An increasing pressure drop can cause compaction of the biomass bed. This compaction, in turn, increases the pressure drop. Once the compaction has started it accelerates almost exponentially (Archambault-Léger and Lynd, 2014; Reynolds and Smirnova, 2018). An irreversible compaction results in the abortion of the process. Such behavior was reported for ground annual lignocellulose, e.g. wheat straw and bagasse, but not for ground softwood and hardwood. A maximum density of $140 \mathrm{~g} / \mathrm{L}$ of ground bagasse allows stable operation (Archambault-Léger and Lynd, 2014). Several strategies to avoid irreversible bed compaction were proposed by Reynolds and Smirnova (2018): The reduction of the fluid velocity, the decrease of the reactor length to diameter ratio and the use of a bed stabilizer reactor (Reynolds and Smirnova, 2018). The latter is a punched plate scaffold inside the reactor that forms separate biomass chambers to avoid the propagation of a compaction. These stabilization strategies indirectly affect other performance parameters, thus require careful consideration. A lower density affects the reactor productivity and the liquid-tosolid ratio. A lower velocity affects the extraction behavior and increases the liquid residence time. Longer residence times may require lower processing temperatures to avoid pentose degradation. The temperature profiles will be strongly affected. The use of a bed stabilizer affects the loading and unloading characteristics.

For a scale-up of fixed-bed reactors for hydrothermal pretreatment, a constant fluid residence time as a scale-up parameter has been used commonly. The largest scale reported is a $300 \mathrm{~L}$ vessel, mentioned earlier. If the liquid residence time is constant, the velocity increases proportionally with the height of the reactor. An increasing fluid velocity unfavorably affects the pressure drop, bed compaction, and axial dispersion. These effects need to be taken into consideration in scale-up.

Techno-economical scale-up studies of FBR based biorefineries conclude beneficial economic performance (Archambault-Léger et al., 2015; Schmidt et al., 2018). Schmidt et al. (2018) determined a minimum reactor number of six: one reactor in operation, four down due to the time requirements to depressurize, unload, clean, load, and preheat the reactor. The sixth reactor is added to account for maintenance reasons. It was calculated that a 150,000 t/a wheat straw scale requires $40 \mathrm{~m}^{3}$ reactors ( 6 in number). The height and diameter of the $40 \mathrm{~m}^{3}$ reactor should be $10.8 \mathrm{~m}$ and $2.2 \mathrm{~m}$, respectively, assuming a height to diameter ratio of 5 . The pretreated and wet biomass would exceed $25 \mathrm{t}$ in weight. This example shows that efficient biomass loading and unloading techniques are required for that scale. The use of a cartridge would add to the weight requiring a heavy-duty crane with a height of approximately $25 \mathrm{~m}$.

The following challenges for the reactor design and operation need to be investigated to progress towards industrialization: (1) An efficient loading and unloading technique needs to be developed to reduce the reactor downtime and improve the handling. We propose the development of screw feeders to load and unload the reactor. (2) The bed compaction must be avoided, and its occurrence better understood. (3) Future research should focus on the strengths of the fixed-bed reactor, which are the high degree of solubilization, and hemicellulose recovery in the liquid stream. For this purpose, lower temperatures and longer liquid residence times are recommended. To promote a homogeneous temperature profile pre-steaming of the biomass bed is suggested.

\subsection{Continuous reactor technology}

Continuous mode of operation is usually preferred at a commercial scale, in order to guarantee a profitable operation. Therefore, testing pretreatment proposals at a pilot scale is a crucial step in the development of technology for commercial applications (Elander, 2013). It is at this scale in which operational issues arise related to momentum, mass and energy transfer. Handling of biomass, operational and process control are other aspects that are also relevant at continuous pilot-scale. All these aspects affect the process safety, environmental impact and profitability of a particular technology.

Continuous pretreatment by means of a screw conveyor reactor (SCR) is a technology alternative, among others, that have been explored during the past years, capitalizing in previous scientific and engineering knowledge from mining, solids handling and pulp and paper industries (Elander, 2013). An important research topic has been to elucidate the effectiveness of this pretreatment technology on making sugars available for downstream processing (i.e., enzymatic digestibility).

\subsubsection{Continuous reactor Technology: Screw conveyor reactor (SCR)}

The screw conveyor reactor (SCR), also referred to as horizontal digester, Pandia digester, continuous tubular reactor (CTR), and others, is a horizontal reactor, that has been developed for the (pre-) treatment of annual lignocellulose with a high solids content. These materials possess disadvantageous transport properties, e.g., the tendency to bridge formation and low bulk density. A schematic drawing with exemplary features is shown in Fig. 3. At one side of the reactor tube, moist biomass is introduced using a high-pressure feeder. Saturated steam is used to bring the mixture to the desired temperature. An Archimedes screw transports the material along the reactor but does not exert any mechanical treatment on the material. At the end of the reactor tube, the material is released. For this purpose, a semi-continuous steam explosion can be used among other release techniques. A detailed 


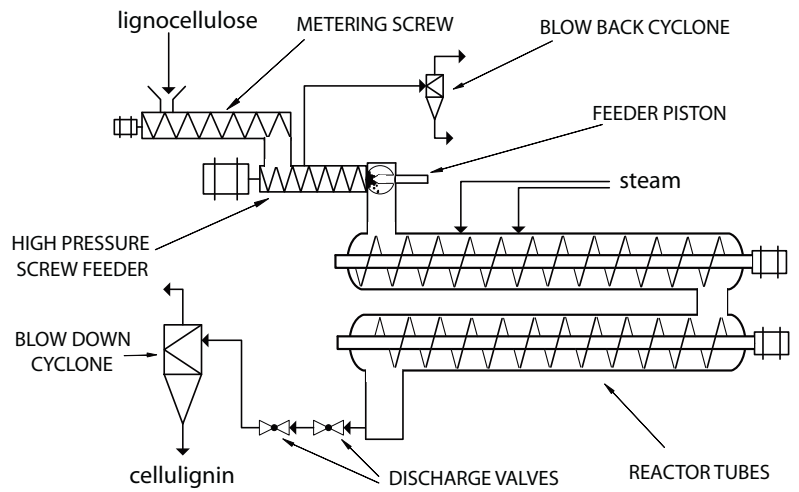

Fig. 3. Schematic drawing of a screw conveyor reactor (SCR), featuring a plug screw feeder, two reactor tubes, and a hot-blow release.

discussion of the engineering aspects of the mode of operation can be found in section 4.3.2.

The SCR has been applied for the first time in the $1960 \mathrm{~s}$ to produce furfural from bagasse by Quaker Oats (Zeitsch, 2000). For this propose, four reactor tubes were stacked on top of each other to allow a residence time of one hour. The combination of several tubes can be used to increase the throughput or residence time. Each tube had a diameter of $1.8 \mathrm{~m}$ and a length of $16 \mathrm{~m}$ resulting in a total volume of $160 \mathrm{~m}^{3}$. Each reactor had a throughput of $60 \mathrm{t} / \mathrm{h}$. Three production lines were installed with two in operation and one available for maintenance. This particular process ran with sulfuric acid and saturated steam at $650{ }^{\circ} \mathrm{C}$ at 10.8 bar. The Pandia digester is an SCR that is used for the pulp production from wheat straw and bagasse, using chemical additives (Rainey and Covey, 2016). The Canadian company Stake Technology Ltd have developed an SCR for the pretreatment of lignocellulose in the 1970 s (Muzzy et al., 1983). This technology has been further developed to the Stake II pretreatment unit that was used with and without the addition of acids (Wayman et al., 1986; Heitz et al., 1991). The Danish company Inbicon has developed an SCR based autohydrolysis pretreatment technology using saturated steam in 2008 (Petersen et al., 2009). This process was based on the IBUS process (Larsen et al., 2008) and has been scaled-up to a nominal throughput of $4 \mathrm{t} / \mathrm{h}$ (Larsen et al., 2012). A treatment temperature of $180-200{ }^{\circ} \mathrm{C}$ with a residence time of 5-15 min was used. Today engineering and plant design solutions based on SCR autohydrolysis are supplied by companies like Andritz (Humbird et al., 2011), Valmet, Metso, AdvanceBio Systems and others on pilot and industrial scales (Humbird et al., 2011; Cheng et al., 2019). Table 3 shows further SCR based pretreatment studies currently found in the literature.

\subsubsection{Mode of operation}

The feeding of the biomass into the reactor requires preliminary conditioning. A pre-steaming hopper can be applied for wood chips preheating, moisturizing, and air removal (Humbird et al., 2011). A water mixing stage is regarded as sufficient for non-woody biomass.

The high-pressure biomass feeding is an integral part of the SCR reactor setup. The feeder should be adapted to the biomass and the reactor design. Biomass feeding must occur by avoiding steam loss and forward leakage of air into the reactor while keeping the reactor sealed. The devices used for SCR are realized as a plug-forming device based on a screw or a reciprocating screw. A comprehensive literature selection on high-pressure biomass feeders has been published by (Dai et al., 2012). The material is metered and dosed into the screw feeder, where it is compressed to form a gas-tight plug. This apparatus can be equipped with a mechanical dewatering section, where air can escape too. The plug is pressed through a narrow channel called throat. The outlet opening of the throat can be closed by a hydraulic piston called choke or blowback preventer. The biomass is only released into the reactor when the axial force in the plug is high enough to move the

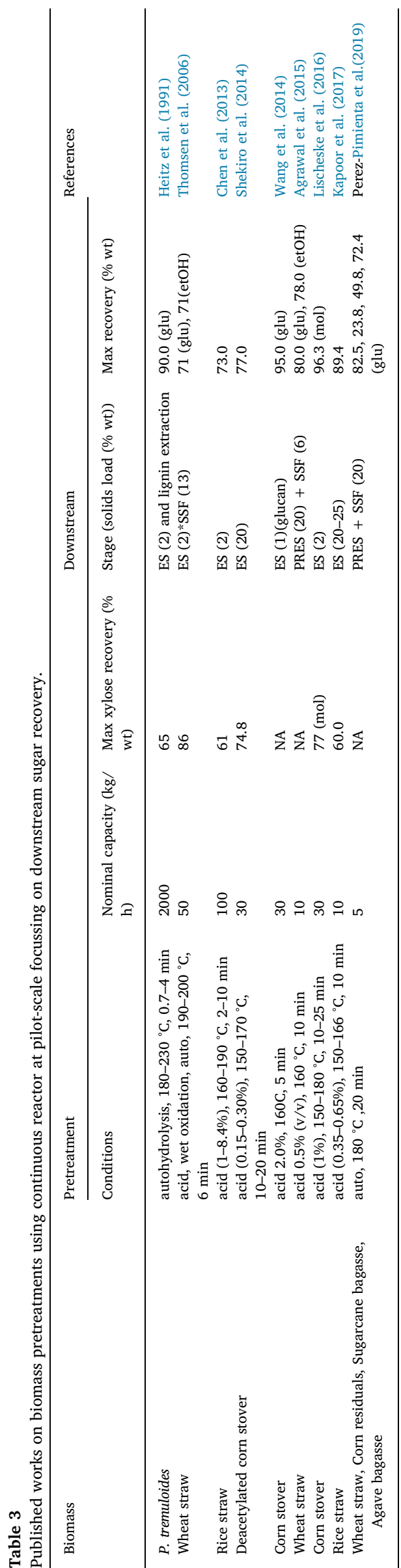


piston. The choke aids in forming a dense plug, it limits the risk of a steam blowback, and it promotes plug breaking. Chokes can be designed with a conical tip for improved performance. The throat can be equipped with knives in the flow direction to improve plug breaking.

Several techniques can be applied to release the treated material to atmospheric pressure. The hot blow pressure release is a semi-continuous steam explosion (Cheng et al., 2019). The material drops into a vertical tube at the end of the reactor. Two ball valves form a lock that periodically releases the material into a blow line. The rapid pressure drop causes the hot water to evaporate and accelerate along the blow line into a cyclone, where solids and vapor are separated. The hot blow can also be realized with a compression screw and a single ball valve (Heitz et al., 1991). For the cold blow technique, water is introduced into the vertical pipe to quench the mixture to a temperature below $100{ }^{\circ} \mathrm{C}$. One ball valve is used to release the slurries exploiting the high reactor pressure. A steam explosion is avoided by applying this technique.

The installed units strongly affect each other, which requires an integrated engineering approach for its design and operation. The plug screw feeder determines the throughput of the plant, while the SCR screw speed determines the residence time and its distribution of the substrate. The rotational speed of the screw feeder only varies in a small range. The volumetric filling degree of the reactor is in the range of $40 \mathrm{vol} \%$ but increased to higher values when a lower screw speed is applied. A combination of different tube geometries can be used, to favor mixing and plug breaking in a first fast-rotating screw (Sievers and Stickel, 2018).

Saturated steam is used to heat the wet biomass to the desired temperature. The steam consumption depends on the feeding rate, moisture content, and preheating temperature. Controlling the pressure of the steam allows simple control of the reactor temperature, exploiting the vapor pressure of water. Heat consumption leads to condensation, which will facilitate fresh steam to flow into the reactor. The flow pattern of steam and biomass is co-current. Preheating reduces steam consumption and reactor pressure fluctuations (Maroušek et al., 2012).

\subsubsection{Performance and Scale-Up}

The measurement and modeling of the residence time distribution (RTD) is a crucial factor in guaranteeing a proper reactor performance. The combination of transportation technologies inside the reactor, biomass size distribution and their rheological properties may produce non-ideal flows. A wide residence time distribution may lead to a dropin yield and an increased production of degradation products.

The RTD in screw conveyor reactors has been investigated for unpressurized (Nachenius et al., 2015) and dilute acid pretreatment of corn stover (Sievers and Stickel, 2018) and autohydrolysis pretreatment of wheat straw and corn stover (Caballero-Barragán et al., 2018; Jaramillo and Sanchez, 2018). A too high volumetric filling degree of the reactor led to a back-slipping of material. The top layer of the biomass rotated, instead of being pushed forward. This way, the screw flights passed by without moving all the material (Nachenius et al., 2015). With a decreasing filling degree, an increasing fraction of the material slipped through the gap between flight and jacket (Sievers and Stickel, 2018). Both effects led to a residence time that was longer than the ideal plug flow residence time. These effects also widened the residence time distribution. Therefore, the filling degree is to be optimized aiming for a narrow residence time distribution. A volumetric filling degree of $40 \mathrm{wt} \%$ is recommended.

Rodriguez et al. (2017) proposed a dynamic model for the xylan depolymerization coupled with the biomass flow rate model of Jaramillo and Sanchez (2018). This first-principles model considers oligomers, monomers, and decomposition products together with $\mathrm{pH}$ and acetic acid. These two models were experimentally validated using wheat straw, corn residuals, and sugar cane bagasse. Ciesielski et al. (2014) and Wang et al. (2014) carried out a comprehensive biomass structural analysis of the effects of acid pretreatment using this SCR technology on corn stover. Physical, chemical, C CP/MAS NMR, sizeexclusion chromatography SFD vibration spectroscopy and multi-scale microscopy techniques were used to correlate structural changes to biomass digestibility.

Most studies consider acid pretreatment of one biomass with the objective of establishing pretreatment and saccharification conditions for maximal sugar recovery after enzymatic saccharification. However, results are difficult to compare because not all reports provide details of the continuous reactor employed, and process conditions of both pretreatment and saccharification stages differ among works. The highest sugar recovery percentages reported reached $95 \%$ of glucose and $77 \%$ of total sugars. These numbers speak out mainly of the mastering of the pilot equipment being employed. A comparison of four different biomasses (wheat straw, corn residuals, sugarcane bagasse and agave bagasse) using the same pretreatment reactor under fixed operating conditions of simultaneous saccharification and fermentation can be found in Perez-Pimienta et al. (2019) for producing bisabolene and bioethanol, respectively. Yield differences up to $40 \%$ were obtained among biomasses.

The scalability of this reactor type was demonstrated already in the 1960 s by Quaker Oats (Zeitsch, 2000). The scale-up in the process development is often based on the severity factor (Overend et al., 1987), since it converts the two most important process parameters temperature and time into one reaction ordinate. Results from batch steam pretreatment can be nearly directly converted to SCR performance (Heitz et al., 1991; Lischeske et al., 2016).

\subsubsection{Limitations}

The limitation of the screw conveyor reactor lay in the challenges to produce experimental data. The scale-down of the reactor to laboratory sizes is not possible. Smallest reactor types show nominal throughputs of $10-40 \mathrm{~kg} / \mathrm{h}$ depending on the producer. The dense biomass plug in the feeding device acts as a dynamic pressure seal. Its rupture leads to blowback of the reactor content. Hot water will begin to boil, resulting in a considerable volumetric flow. A more significant risk is the blow out of the steam generator. Therefore, installations are required to prevent damages in a blowback event. A blowback pipe attached to the feeder can lead the accelerated material to a cyclone to separate solids and safely release steam to the top. A dense and stable plug is required to prevent a blowback event. Thus, the volumetric flow to the feeder must be controlled precisely. The SCR is designed for a specific type of substrate. A change in feedstock density, particle size, and rigidity and preparation requirements is challenging. The introduction of non-condensable gases into the steam atmosphere lowers the temperature at constant reactor pressure. The formation of volatiles like furfural and acetic acid may require a gas purge. This is more likely for cold blow since a steam leakage is prevented. Abrasive feedstocks, e.g., straws and bagasse, lead to increased wear in the plug feeder. This may result in short maintenance intervals. The continuous autohydrolysis may still be affected by low sugar yields and degradations reactions. A two-step pretreatment was proposed based on SCR technology, to achieve a full fractionation of the hemicellulose and cellulose-derived sugars (Conrad et al., 2019).

\subsection{Comparison of reactor technologies}

The SCR is rather tightly bound to one type of substrate, compared to (semi-) batch reactors. Also, the integration of feeding and release devices is complicated. The specific thermal energy demand is lowest for the SCR since it operates a high solids content with constant reactor temperature. The scalability of the SCR has been successfully demonstrated whereas it is not clear to which scales the FBR and SE can be built. The reactor size of the SCR can be relatively small, due to the continuous operation and short residence times. The operation at the vapor pressure of water or SE and SCR potentially reduces the wall 
thickness compared to fixed-bed reactors.

Despite the knowledge of advantageous and disadvantageous, evaluation and comparison of these autohydrolysis reactor technologies are only meaningful in a techno-economical optimization study for a complete biorefinery plant. Harvesting and logistics, as well as heat integration and downstream processing routs, must be included. Regarding the operation in different scales, it is assumed that the SE and FBR show high potential in small production scales with a flexible feedstock, while the SCR is best suited in a large-scale operation.

\section{Hydrothermal pilot plant in the Brazilian Biorenewables National Laboratory: Case study}

In an attempt to development of biorefinery industry, the pretreatment is one of the most significant bottlenecks due to the recalcitrant structure of biomass and has as its main challenge to provide high-efficiency biomass fractionation combining energy efficiency, environmental sustainability, and economic viability (Baruah et al., 2018). Therefore, more studies are necessary to improve the reactor design, and pretreatment operational strategies. In this context, the LNBR (Brazilian Biorenewables National Laboratory) has a pilot plant that aims to verify and demonstrate technological routes for the production of high added value compounds as: preparation of polyurethane composites reinforced with cellulose or lignin, xylooligosaccharides as prebiotic; and biofuels as ethanol production in terms of biorefinery. The pilot plant has three fully automated pretreatment reactors, and it is possible to evaluate strategies with and without separation of the solubilized stream after pretreatment stage. Two of them are for steam explosion process being one continuous and another hydrothermal batch operation mode, both already commissioned and entirely operational (Rocha et al. 2015; de Menezes et al. 2016a; Miléo et al. 2016; de Menezes et al. 2016b; Nascimento et al. 2017; Nakanishi et al. 2018).

The continuous steam explosion reactor operates at a feed rate from 8 to $35 \mathrm{~kg} / \mathrm{h}$ (dry base), the temperature range between 140 and $190^{\circ} \mathrm{C}$, residence time according to the biomass fractionation. Some autohydrolysis pretreatments of sugarcane bagasse performed in this reactor achieved cellulose recoveries above $90 \%$ in the solid fraction "cellulignin" and solubilization around $30 \%$ of the initial sugarcane bagasse, the liquid is mostly composed of C5 sugars and degradation products. Moreover, it is possible to operate the reactor under conditions that promote the obtaining of C5 sugars in monomeric form while minimizing HMF and furfural formation (see Fig. 1, that illustrates how this is relevant for biorefining).

The first of the two batch hydrothermal reactors operate coupled to a cyclone, and its maximum temperature of operation is $210{ }^{\circ} \mathrm{C}$. With the operation of this reactor is possible to obtain sugarcane bagasse fractioning comparable with the achieved at the continuous steam explosion; however, the enzymatic digestibility of the pretreated solids presents significant differences (unpublished data). The other hydrothermal reactor - which relies on liquid hot water-is heated through of flowing steam injection or thermal oil in a reactor's jacket, the reactor has a condensation system, mechanical agitation (30 to $170 \mathrm{rpm}$ ), the maximum temperature operation is of $200{ }^{\circ} \mathrm{C}$. As shown in previous works (Rocha et al., 2012; Rocha et al., 2015; de Menezes et al., 2016b; Nascimento et al., 2017; Nakanishi et al., 2018) this reactor has already operated with sugarcane bagasse and straw under various temperature and time conditions, with and without the addition of catalysts, and at several liquid:biomas ratios. As an example, the mass balance of reaction at $190{ }^{\circ} \mathrm{C}, 10 \mathrm{~min}$, and liquid:biomass ratio (1:10) presented a recovery of $90 \%$ of the cellulose in the cellulignin. Approximately $60 \%$ of the C5 sugars were recovered in the hemicellulosic hydrolyzate, and $56 \%$ of the total sugars in the liquid fraction as oligomers, and nearly $13 \%$ of the lignin was solubilized (Nascimento et al., 2017). These works provide the basis for the commissioning of the continuous hydrothermal pretreatment reactor and its application at industrial level.

\section{Biorefinery integrated process design using hydrothermal pretreatment}

In previous work by Torres et al. (2017) was discussed the main approaches that have been used to model the different types of lignocellulosic biomass in terms of process design, techno-economic analysis of hydrothermal pretreatment with details that allow a meaningful comparison between different options, how to model the pretreatment reactor itself in terms of the reactions that are considered (stoichiometries and kinetics), and discussed general features of process flowsheets that include hydrothermal pretreatment, focusing on the rationale of upstream and downstream operations and the consequences these choices have. From the process design point of view, hydrothermal processing shares many common features with dilute acid hydrolysis, in the sense that the reaction is also a hydronium-based hydrolysis. Then, the presence of acidic media must be accounted for when designing the reactor and de-fining the materials. Operation at higher temperatures and pressures requires extra care in the design phase. Hydrothermal-pretreatment reactors should not be evaluated in isolation of the other unit operations in the process flowsheet as upstream operations, especially if biological processes are involved in downstream processing (separation/purification). This point is important as some works focus on the economics of the reactor itself, forgetting that savings in the reactor are usually the cause of more expensive separation steps. Fig. 4 shows the process flowsheets that include hydrothermal pretreatment in terms of biorefinery integrated process design and heat integration.

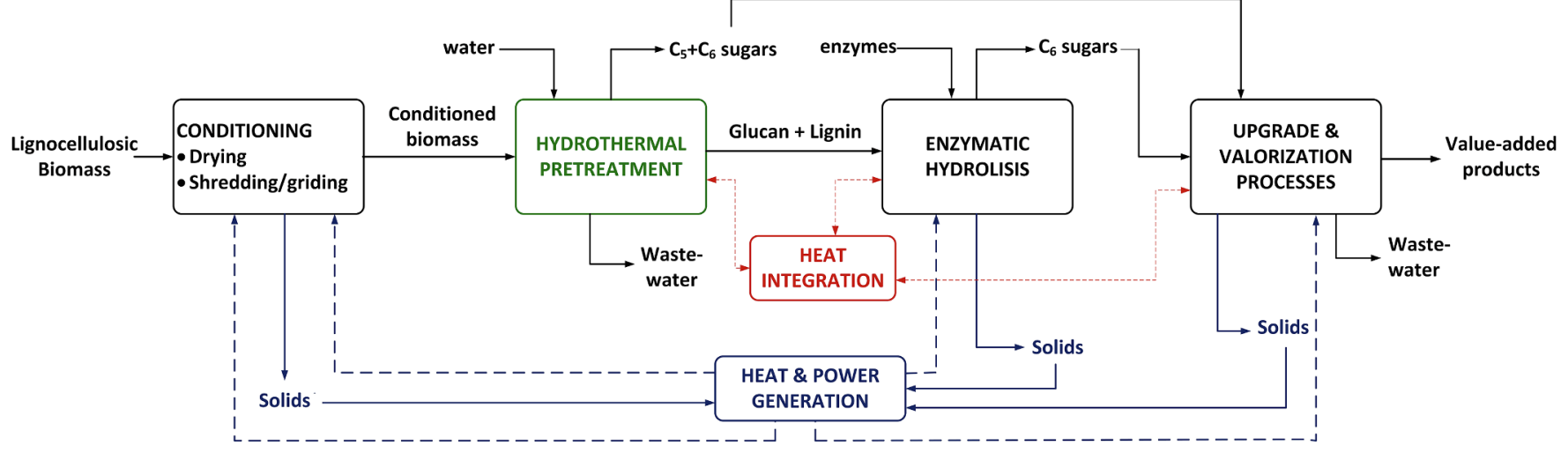

Fig. 4. Flowsheets that include hydrothermal pretreatment in terms of biorefinery integrated process design and heat integration. 


\subsection{Hydrothermal pretreatment for processing a single lignocellulosic feedstock to C5 + C6 sugars}

This is the most traditional application of hydrothermal pretreatment, and although most of the literature in the area focuses in this type of process, many of the findings (especially those that apply to design) should be applicable to other combinations of feedstocks and products. The overall process flowsheet must include a first section that reduces its size; the second section is the hydrothermal pretreatment itself that in which hemicelluloses are separated from cellulose and lignin; the third section is an enzymatic hydrolysis that depolymerizes cellulose into glucose; glucose might be upgraded to fuels or other chemicals in additional downstream sections (Fig. 4). In general, two other sections are also included: one for heat recovery/integration (i.e. steam/ hot water exiting section 2 is used to pre-heat feeds) and another one for burning residual organic solids (e.g. lignin and unreacted cellulose) to generate steam and power. Process designs that do not stop at production of monomeric sugars also include downstream sections for their upgrade.

\subsubsection{General considerations for reaction system design of lignocellulosic feedstocks}

Once the type of hydrothermal reactor is selected (Batch reactor, semi-continuous reactor, continuous reactor), there are two limiting options in term of modelling the reactor: rigorous and yield based. Rigorous modelling should consider at least the kinetics of the reaction, and better yet include some detailed mass and heat transfer mechanisms. In this case reactor sizing is performed by considering the kinetics and reactor load and the reactor sizing is performed by considering the desired throughput and a selected residence time. Evidently, a kinetic based approach should always be preferred, as it provides better estimates and allows for the study of different reaction/separation configurations. However, many times experimental data are not enough to propose a reasonable kinetic model and may not even be a requirement if the goal is to have a very preliminary techno-economic study with the aim of having an order of magnitude estimate of an overall processing cost. Tao et al. (2011) and Larnaudie et al. (2019) reported that the hydrothermal pretreatment (LHW) had a good economic performance in the bioethanol production from lignocellulosic biomass compared to other pretreatments as dilute acid and soaking in aqueous ammonia.

Some studies that include kinetic-based modelling useful for reactor/process design have been reported by Prunescu et al. (2015), Reynolds and Smirnova, (2018) and Conrad et al. (2019). Conrad et al. (2019) reported a kinetic model derived from experimental data for hydrothermal pretreatment of wheat straw where the constants depend on the severity factor. Reynolds and Smirnova (2018) detailed a model that considers kinetics as well as mass and heat transfer for the modelling of a flow-through reactor that pretreats pelletized wheat straw. The study mentions that the model has been at $185-215{ }^{\circ} \mathrm{C}$ and the authors claim prediction accuracies between 0.013 and $0.02 \mathrm{~kg} / \mathrm{kg}$ biomass) for hemicellulose oligomers and 0.0008 and $0.004 \mathrm{~kg} / \mathrm{kg}$ biomass) for monomers. The alternative kinetic model accounts for the individual species that that are formed during the hydrothermal pretreatment and includes: polymers (cellulose, arabinan, xylan), oligomers (from xylose), monomers (arabinose, glucose, xylose), as well as other compounds (acetyls, lumped organic acids, 5-HMF, pseudo-lignin, furfural, other lumped degradation products) (Prunescu et al. 2015). This study calculates the kinetic constants and energies of activation of the individual reactions within the $178-185{ }^{\circ} \mathrm{C}$ range. Interestingly, there is not an explicit reference of which biomass was used for derivation of the model.

Although derivation of the previous models is justified as a required input for economic analysis, none of these references explicitly report the results of such analysis. However, Conrad et al. (2019) does include a discussion on the estimation of capital expenses that is worth discussing. First, the authors select the screw conveyor reactor (SCR) and the extruder as the most promising reactor types and propose three different flowsheets in which these are combined with themselves and washing units. For each option the authors utilize the kinetic model derived by them to estimate the yields of hydrolysate, lignin and furfural (as an unwanted contaminant) at different temperatures which is identified in the study as the most relevant parameter as it affects reaction pressure and residence time. The interesting point is that capital expenses for each option are indirectly compared by estimating the amount of mass of reactor required by each, where this mass is a function of both residence time (which influences reactoŕs volume) and pressure (which influences reactoŕs wall thickness). The authors finally conclude that the choice of reaction temperature dominates the choice of the number of stages regarding the reactor size. A concept with three stages at $215{ }^{\circ} \mathrm{C}$ resulted in $481 \mathrm{~kg}$, while concepts with only one or two reactor stages resulted in substantially more steel consumption, caused by the lower reaction temperatures.

\subsection{Hydrothermal pretreatment for processing mixed lignocellulosic feedstocks to C5 + C6 sugars}

Current work in the area has shifted from studying the economics of processing single feedstocks to study the economic performance of plants that can process multiple feedstocks. Along these lines two relevant works are those by Nieder-Heitmann et al. (2019) and Ashraf and Schmidt, (2018). As mentioned by Ashraf and Schmidt, (2018) considering biorefineries that can handle multiple feedstocks is very relevant as in many regions the amounts produced by a single source are not enough to propose a plant of a reasonable capacity. When multiple feedstocks are to be processed there are two limiting design strategies that can be chosen: 1) Process each feedstock as a single feedstock, selecting operational conditions that are optimal for that feedstock, and switch to another feedstock and operational conditions once processing of the first feedstock is finished. This mode of operation is particularly suitable for seasonal feedstocks. Optimal scheduling of the operations becomes the most relevant design parameter, the rest of the design is as before; 2) Mix the feedstocks for co-processing. This option requires further understanding of the synergies that might arise between the feedstocks and how different mixing proportions affect the overall result and has been the focus of the most recent work. Elliston et al. (2015) studied the effect of mixing waste copier paper and wheat in steam explosion pretreatment and found a reduction of $\sim 40 \%$ in the production of inhibitors such as acetic and formic acids and furfural, while Pereira et al. (2015) reported an increase in the enzymatic conversion of sugars, the authors claim to be due to the mixing of sugarcane bagasse with straw and tops. Inspired by these works, Ashraf and Schmidt, (2018) performed a techno-economic evaluation of a hydrothermal pretreatment -based biorefinery that considered a mix of woody (palm fronds) and green lignocellulosic residues (Bermuda grass and Jasmine hedges). The flowsheet studied by the authors consists of the three sections and an additional one for generation of heat and power. Experimental conversion data from their own labs was used to model the reactors. The authors studied six different cases: three mixtures of the lignocellulosic biomass in different proportions, and the three "pure" feeds, and found that the costs (both CAPEX and OPEX) for the six options were comparable, but the yields in the "mixed" studies were better. Hence, they concluded that mixing the feedstocks was advantageous. In another contribution Nieder-Heitmann et al. (2019) studied the co-processing of sugarcane bagasse and trash $(60: 40)$, this study was analyzed for production of succinic acid and electricity. In this case, the goal of the work was to compare the economics of the different pretreatment options, and several very detailed process flowsheets, with the corresponding models and data used. The authors conclude that although not being the most economical in terms of capital expenses, steam explosion was the most profitable option, basically because it was the one that provided the best succinic acid yields. However, it must be mentioned that different scales and reaction 
conditions were used for each case study, thus care must be taken before claiming a general statement.

\subsection{Integrated process design - heat integration of hydrothermal pretreatment prior to anaerobic digestion}

Hydrothermal pretreatment has also been studied as a way to enhance biogas production prior to anaerobic digestion processes. This fact has been experimentally verified and there is a general consensus in the literature that, regardless the type of biomass used, there is a net increase in the biogas produced if a pretreatment reactor is installed before the anaerobic digestor. Kutsay et al. (2016) studied thermal expansionary pretreatment (closely related to steam explosion) of wheat straw and analyzed the effects of it in a plant that by anaerobic digestion is designed to produce $500 \mathrm{~kW}$ of heat. The first finding is that by including the pretreatment unit the plant is able now to produces $750 \mathrm{~kW}$ of heat. In terms of cost, their results show that the pretreatment unit by itself represents $36 \%$ of the total equipment cost and that it increases the payback period from 17 years (plant without pretreatment), to 25 years (plant with pretreatment). Their conclusion is that inclusion of the plant does not look optimistic from the commercial point of view, but that better economics are possible if more products form the plant can be sold in terms of biorefinery concept.

He et al. (2017) studied the net energy balance and the energy for methane production from rice straw using hydrothermal pretreatment (150-210 $\left.{ }^{\circ} \mathrm{C}, 0-30 \mathrm{~min}\right)$. They reported that highest net energy gain was $2741 \mathrm{MJ} / \mathrm{t}$, and the energy ratio and energy recovery were 2.7 and $30.7 \%$, respectively. At first view, from these results it can be inferred that from the energy balance point of view, simple anaerobic digestion is still more convenient. However, it has to be noted that this are batch lab scale calculations and not process design calculations, meaning that there is room for improvement of the energy balance if for example some of the energy in the outlet stream of the hydrothermal reactor is recovered for use in the anaerobic digestor. Techniques such as pinch analysis could be used for an assessment of the minimum energy required by the system, which would provide the best-case energy balance.

\section{Conclusions}

Hydrothermal pretreatment of lignocellulosic biomass is one of the most promising technologies to be used at different scales in the processing of biomass for fractionation and structural modification for the development of integrated, sustainable biorefineries and the circular Bioeconomy. Therefore, the development in process engineering for hydrothermal pretreatment process is fundamental in order to understand the correct approaches needed to advance this technology to a commercial application for second generation biorefineries in the production of high added value compounds and biofuels.

\section{Declaration of Competing Interest}

The authors declare that they have no known competing financial interests or personal relationships that could have appeared to influence the work reported in this paper.

\section{Acknowledgments}

The authors gratefully thank the Secretary of Public Education of Mexico - Mexican Science and Technology Council (SEP-CONACYT, Mexico) for the Basic Science Project -2015-01 (Ref. 254808), Energy Sustainability Fund 2014-05 (CONACYT-SENER), Mexican Centre for Innovation in Bioenergy (Cemie-Bio), Cluster of Bioalcohols (Ref. 249564) and the BMBF for the financial support (reference number: 031B0660A).

\section{Author Contributions}

Héctor Ruiz contributed to design and conceptualization of the review, compilation, and editing of the manuscript. Héctor Ruiz, Marc Conrad, Shao-Ni Sun, Arturo Sanchez, George Rocha, Aloia Romaní, Eulogio Castro, Ana Torres, Rosa Rodríguez-Jasso, Liliane Andrade, Irina Smirnova, Run-Cang Sun and Anne Meyer contributed to writing (including tables and figures) and review of the manuscript.

\section{References}

Agbor, V.B., Cicek, N., Sparling, R., Berlin, A., Levin, D.B., 2011. Biomass pretreatment: fundamentals toward application. Biotechnol. Adv. 29, 675-685.

Agrawal, R., Satlewal, A., Gaur, R., Mathur, A., Kumar, R., Gupta, R.P., Tuli, D.K., 2015 Pilot scale pretreatment of wheat straw and comparative evaluation of commercial enzyme preparations for biomass saccharification and fermentation. Biochem. Eng. J. 102, 54-61.

Aguilar, D.L., Rodríguez-Jasso, R.M., Zanuso, E., Lara-Flores, A.A., Aguilar, C.N., Sánchez, A., Ruiz, H.A., 2018a. Operational Strategies for Enzymatic Hydrolysis in a Biorefinery. In: Kumar, S., Sani, R. (Eds.), Biorefining Biomass to Biofuels Opportunities and Perception. Springer, Cham, pp. 223-248.

Aguilar, D.L., Rodríguez-Jasso, R.M., Zanuso, E., de Rodríguez, D.J., Amaya-Delgado, L., Sanchez, A., Ruiz, H.A., 2018b. Scale-up and evaluation of hydrothermal pretreatment in isothermal and non-isothermal regimen for bioethanol production using agave bagasse. Bioresour. Technol. 263, 112-119.

Aguilar-Reynosa, A., Romaní, A., Rodríguez-Jasso, R.M., Aguilar, C.N., Garrote, G., Ruiz, H.A., 2017. Comparison of microwave and conduction-convection heating autohydrolysis pretreatment for bioethanol production. Bioresour. Technol. 243, 273-283.

Amendola, D., De Faveri, D.M., Egües, I., Serrano, L., Labidi, J., Spigno, G., 2012. Autohydrolysis and organosolv process for recovery of hemicelluloses, phenolic compounds and lignin from grape stalks. Bioresour. Technol. 107, 267-274.

Archambault-Léger, V., Lynd, L.R., 2014. Fluid mechanics relevant to flow through pretreatment of cellulosic biomass. Bioresour. Technol. 157, 278-283.

Arévalo, C., Freer, J., Naulin, P.A., Barrera, N.P., Troncoso, E., Araya, J., Peña-Farfal, C., Castillo, R.P., 2017. Study of the ultrastructure of Eucalyptus globulus wood substrates subjected to auto-hydrolysis and diluted acid hydrolysis pre-treatments and its influence on enzymatic hydrolysis. Bioenergy Res. 10, 714-727.

Ashraf, M.T., Schmidt, J.E., 2018. Process simulation and economic assessment of hydrothermal pretreatment and enzymatic hydrolysis of multi-feedstock

lignocellulose-Separate vs combined processing. Bioresour. Technol. 249, 835-843.

Baruah, J., Nath, B.K., Sharma, R., Kumar, S., Deka, R.C., Baruah, D.C., Kalita, E., 2018 Recent trends in the pretreatment of lignocellulosic biomass for value-added products. Front. Energy Res. 6, 1-19.

Bhutto, A.W., Qureshi, K., Harijan, K., Abro, R., Abbas, T., Bazmi, A.A., Karim, S., Yu, G., 2017. Insight into progress in pre-treatment of lignocellulosic biomass. Energy 122, 724-745.

Bobleter, O.D., Pape, G., 1968. Verfahren zum Abbau von Holz, Rinde oder anderen Pflanzenmaterialien [Process for the degradation of wood, bark, or other plant materials]. Aust, Pat, pp. 263661.

Caballero-Barragán, H., Osuna-Ibarra, L., Sanchez, A., Loukianov, A.G., 2018. Semi-empirical modelling of the mass flow in a pilot-scale tubular reactor and tracking control. J. Process Control 69, 79-85.

Cabeza, A., Piqueras, C.M., Sobrón, F., García-Serna, J., 2016. Modeling of biomass fractionation in a lab-scale biorefinery: Solubilization of hemicellulose and cellulose from holm oak wood using subcritical water. Bioresour. Technol. 200, 90-102.

Cebreiros, F., Ferrari, M.D., Lareo, C., 2019. Cellulose hydrolysis and IBE fermentation of eucalyptus sawdust for enhanced biobutanol production by Clostridium beijerinckii DSM 6423. Ind. Crops Prod. 134, 50-61.

Chen, W.H., Tsai, C.C., Lin, C.F., Tsai, P.Y., Hwang, W.S., 2013. Pilot-scale study on the acid-catalyzed steam explosion of rice straw using a continuous pretreatment system. Bioresour. Technol. 128, 297-304.

Chen, X., Li, H., Sun, S., Cao, X., Sun, R., 2016. Effect of hydrothermal pretreatment on the structural changes of alkaline ethanol lignin from wheat straw. Sci. Rep. 6, 39354.

Chen, H., Sui, W., 2017. Steam explosion as a hydrothermal pretreatment in the biorefinery concept. In: Ruiz, H.A., Thomsen, M.H., Trajano, H.L. (Eds.), Hydrothermal Processing in Biorefineries. Springer International Publishing, Switzerland, pp. 317-332.

Chen, X., Li, H., Sun, S., Cao, X., Sun, R., 2018. Co-production of oligosaccharides and fermentable sugar from wheat straw by hydrothermal pretreatment combined with alkaline ethanol extraction. Ind. Crop. Prod. 111, 78-85.

Cheng, M.-H., Dien, B.S., Lee, D.K., Singh, V., 2019. Sugar production from bioenergy sorghum by using pilot scale continuous hydrothermal pretreatment combined with disk refining. Bioresour. Technol. 289, 121663.

Chornet, E., Overend, R.P., 2017. How the severity factor in biomass hydrolysis came about. In: Ruiz, H.A., Thomsen, M.H., Trajano, H.L. (Eds.), Hydrothermal Processing in Biorefineries. Springer, Cham, pp. 1-3.

Ciesielski, P.N., Wang, W., Chen, X., X., Vinzant, T.B. Melvin P Tucker, M.P., Decker, S.R. Himmel, M.E., David K Johnson, D.K., Donohoe B.S., 2014. Effect of mechanical disruption on the effectiveness of three reactors used for dilute acid pretreatment of corn stover Part 2: morphological and structural substrate analysis. Biotechnol. Biofuels. 7, 47. 
Cocero, M.J., Cabeza, Á., Abad, N., Adamovic, T., Vaquerizo, L., Martínez, C.M., PazoCepeda, M.V., 2018. Understanding biomass fractionation in subcritical \& supercritical water. J. Supercrit. Fluid. 133, 550-565.

Conde, E., Fang, W., Hemming, J., Willför, S., Domínguez, H., Parajó, J.C., 2014. Recovery of bioactive compounds from Pinus pinaster wood by consecutive extraction stages. Wood Sci. Technol. 48, 311-323.

Conrad, M., Häring, H., Smirnova, I., 2019. Design of an industrial autohydrolysis pretreatment plant for annual lignocellulose. Biomass Convers. Biorefin. In press. Doi. org/10.1007/s13399-019-00479-1.

Cubas-Cano, E., González-Fernández, C., Tomás-Pejó, E., 2019. Evolutionary engineering of Lactobacillus pentosus improves lactic acid productivity from xylose-rich media at low pH. Bioresour. Technol. 288, 121540.

Cunha, J.T., Soares, P.O., Romaní, A., Thevelein, J.M., Domingues, L., 2019. Xylose fermentation efficiency of industrial Saccharomyces cerevisiae yeast with separate or combined xylose reductase/xylitol dehydrogenase and xylose isomerase pathways. Biotechnol. Biofuels. 12, 1.

Dai, J., Cui, H., Grace, J.R., 2012. Biomass feeding for thermochemical reactors. Prog. Energy Combust. Sci. 38, 716-736.

d'Errico, C., Börjesson, J., Ding, H., Krogh, K.B.R.M., Spodsberg, N., Madsen, R., Monrad, R.N., 2016. Improved biomass degradation using fungal glucuronoyl-esterases-hydrolysis of natural corn fiber substrate. J Biotechnol. 219, 117-123.

DeMartini, J.D., Pattathil, S., Avci, U., Szekalski, K., Mazumder, K., Hahn, M.G., Wyman, C.E., 2011. Application of monoclonal antibodies to investigate plant cell wall deconstruction for biofuels production. Energ. Environ. Sci. 4, 4332-4339.

de Menezes, F.F., da Silva Fernandes, R.H., de Moraes Rocha, G.J., Maciel Filho, R., 2016a. Physicochemical characterization of residue from the enzymatic hydrolysis of sugarcane bagasse in a cellulosic ethanol process at pilot scale. Industrial Crops and Products 94, 463-470.

de Menezes, F., Rocha, G., Maciel Filho, R., 2016b. Obtainment and characterization of lignin from enzymatic hydrolysis of sugarcane bagasse of $2 \mathrm{G}$ ethanol process in pilot scale. Chem. Eng. Trans. 50, 397-402.

Djajadi, D.T., Hansen, A.R., Jensen, A., Thygesen, L.G., Pinelo, M., Meyer, A.S., Jørgensen, H., 2017. Surface properties correlate to the digestibility of hydrothermally pretreated lignocellulosic Poaceae biomass feedstocks. Biotechnol. Biofuels. 10, 49.

Donohoe, B.S., Decker, S.R., Tucker, M.P., Himmel, M.E., Vinzant, T.B., 2008. Visualizing lignin coalescence and migration through maize cell walls following thermochemical pretreatment. Biotechnol. Bioeng. 101, 913-925.

Elander, R.T., 2013. Experimental pretreatment systems from laboratory to pilot scale. In: Wyman, C.E. (Ed.), Aqueous pretreatmet of plant biomass for biological and chemical conversion to fuels and chemicals. John Wiley \& Sons, Ltd., United Kindom, pp. 417-450.

Elliston, A., Wilson, D.R., Wellner, N., Collins, S.R., Roberts, I.N., Waldron, K.W., 2015 Effect of steam explosion on waste copier paper alone and in a mixed lignocellulosic substrate on saccharification and fermentation. Bioresour. Technol. 187, 136-143.

Garrote, G., Domínguez, H., Parajó, J.C., 1999. Hydrothermal processing of lignocellulosic materials. Holz Roh Werkst. 57, 191-202.

Gonçalves, F.A., dos Ruiz, H.A., Santos, E.S., Teixeira, J.A., de Macedo, G.R., 2015. Bioethanol production from coconuts and cactus pretreated by autohydrolysis. Ind. Crops. Prod. 77, 1-12.

Gullón, B., Yáñez, R., Alonso, J.L., Parajó, J.C., 2010. Production of oligosaccharides and sugars from rye straw: a kinetic approach. Bioresour. Technol. 101, 6676-6684.

Gullón, P., Romaní, A., Vila, C., Garrote, G., Parajó, J.C., 2012. Potential of hydrothermal treatments in lignocellulose biorefineries. Biofuels Bioprod. Biorefin. 6, 219-232.

Gullón, B., Eibes, G., Moreira, M.T., Dávila, I., Labidi, J., Gullón, P., 2017. Antioxidant and antimicrobial activities of extracts obtained from the refining of autohydrolysis liquors of vine shoots. Ind. Crops Prod. 107, 105-113.

He, L., Huang, H., Lei, Z., Lin, B., 2017. Energy recovery from rice straw through hydrothermal pretreatment and subsequent biomethane production. Energy Fuels. 31, 10850-10857.

Heitz, M., Capek-Ménard, E., Koeberle, P.G., Gagné, J., Chornet, E., Overend, R.P., Taylor, J.D., Yu, E., 1991. Fractionation of Populus tremuloides at the pilot plant scale: Optimization of steam pretreatment conditions using the STAKE II technology. Bioresour. Technol. 35, 23-32.

Hijosa-Valsero, M., Garita-Cambronero, J., Paniagua-García, A.I., Díez-Antolínez, R., 2018. Biobutanol production from coffee silverskin. Microb. Cell Fact. 17, 1-9.

Holopainen-Mantila, U., Marjamaa, K., Merali, Z., Käsper, A., de Bot, P., Jääskeläinen, A. S., Waldron, K., Kruus, K., Tamminen, T., 2013. Impact of hydrothermal pre-treatment to chemical composition, enzymatic digestibility and spatial distribution of cell wall polymers. Bioresour. Technol. 138, 156-162.

Humbird, D., Davis, R., Tao, L., Kinchin, C., Hsu, D., Aden, A., Schoen, P., Lukas, J., Olthof, B., Worley, M., Sexton, D., Dudgeon, D., 2011. Process design and economics for biochemical conversion of lignocellulosic biomass to ethanol: Dilute-acid pretreatment and enzymatic hydrolysis of corn stover (No. NREL/TP-5100-47764). https://www.nrel.gov/docs/fy11osti/47764.pdf.

Hu, F., Jung, S., Ragauskas, A., 2012. Pseudo-lignin formation and its impact on enzymatic hydrolysis. Bioresour. Technol. 117, 7-12.

Ingram, T., Rogalinski, T., Bockemühl, V., Antranikian, G., Brunner, G., 2009. Semicontinuous liquid hot water pretreatment of rye straw. J. Supercrit. Fluids. 48, 238-246.

Jacquet, N., Maniet, G., Vanderghem, C., Delvigne, F., Richel, A., 2015. Application of steam explosion as pretreatment on lignocellulosic material: a review. Ind. Eng. Chem. Res. 54, 2593-2598.

Jacquet, N., Richel, A., 2017. Adaptation of severity factor model according to the operating parameter variations which occur during steam explosion process. In: Ruiz, H.A., Thomsen, M.H., Trajano, H.L. (Eds.), Hydrothermal Processing in Biorefineries.
Springer International Publishing, Switzerland, pp. 333-351.

Jaramillo, I., Sanchez, A., 2018. Mass flow dynamic modeling and residence time control of a continuous tubular reactor for biomass pretreatment. ACS Sustain. Chem. Eng. 6 , 8570-8577.

Jesus, M.S., Genisheva, Z., Romaní, A., Pereira, R.N., Teixeira, J.A., Domingues, L., 2019. Bioactive compounds recovery optimization from vine pruning residues using conventional heating and microwave-assisted extraction methods. Ind. Crops Prod. 132, 99-110.

Jung, S., Trajano, H.L., Yoo, C.G., Foston, M.B., Hu, F., Tolbert, A.K., Wyman, C.E., Ragauskas, A.J., 2018. Topochemical understanding of lignin distribution during hydrothermal flowthrough pretreatment. ChemistrySelect. 3, 9348-9352.

Kapoor, M., Soam, S., Agrawal, R., Gupta, R.P., Tuli, D.K., Kumar, R., 2017. Pilot scale dilute acid pretreatment of rice straw and fermentable sugar recovery at high solid loadings. Bioresour. Technol. 224, 688-693.

Kapu, N.S., Yuan, Z., Chang, X.F., Beatson, R., Martinez, D.M., Trajano, H.L., 2016. Insight into the evolution of the proton concentration during autohydrolysis and dilute-acid hydrolysis of hemicellulose. Biotechnol. Biofuels. 9, 224.

Kilpeläinen, P.O., Hautala, S.S., Byman, O.O., Tanner, L.J., Korpinen, R.I., Lillandt, M.K.J., Pranovich, A.V., Kitunen, V.H., Willför, S.M., Ilvesniemi, H.S., 2014. Pressurized hot water flow-through extraction system scale up from the laboratory to the pilot scale. Green Chem. 16, 3186-3194.

Kristensen, J.B., Thygesen, L.G., Felby, C., Jørgensen, H., Elder, T., 2008. Cell-wall structural changes in wheat straw pretreated for bioethanol production. Biotechnol. Biofuels. 1, 5.

Kutsay, A., Kratky, L., Jirout, T., 2016. Energy-economic analysis of thermal-expansionary pretreatment for its implementation at a biogas plant. Chem. Eng. Technol, $39,2284-2292$.

Lara-Flores, A.A., Araújo, R.G., Rodríguez-Jasso, R.M., Aguedo, M., Aguilar, C.N., Trajano, H.L., Ruiz, H.A., 2018. Bioeconomy and biorefinery: valorization of hemicellulose from lignocellulosic biomass and potential use of avocado residues as a promising resource of bioproducts. In: Singhania, R., Agarwal, R., Kumar, R., Sukumaran, R. (Eds.), Waste to Wealth. Springer, Singapore, pp. 141-170.

Larnaudie., V. Ferrari, M.D., Lareo, C., 2019. Techno-economic analysis of a liquid hot water pretreated switchgrass biorefinery: Effect of solids loading and enzyme dosage on enzymatic hydrolysis. Biomass Bioenergy. 130, 105394.

Larsen, J., Østergaard Petersen, M., Thirup, L., Wen Li, H., Krogh Iversen, F., 2008. The IBUS Process - Lignocellulosic bioethanol close to a commercial reality. Chem. Eng. Technol. 31, 765-772.

Larsen, J., Haven, M.Ø., Thirup, L., 2012. Inbicon makes lignocellulosic ethanol a commercial reality. Biomass Bioenergy. 46, 36-45.

Li, H., Pu, Y., Kumar, R., Ragauskas, A.J., Wyman, C.E., 2014. Investigation of lignin deposition on cellulose during hydrothermal pretreatment, its effect on cellulose hydrolysis, and underlying mechanisms. Biotechnol. Bioeng. 111, 485-492.

Li, M., Cao, S., Meng, X., Studer, M., Wyman, C.E., Ragauskas, A.J., Pu, Y., 2017. The effect of liquid hot water pretreatment on the chemical-structural alteration and the reduced recalcitrance in poplar. Biotechnol. Biofuels. 10, 237.

Li, H.-Y., Wang, B., Wen, J.-L., Cao, X.-F., Sun, S.-N., Sun, R.C., 2018. Availability of four energy crops assessing by the enzymatic hydrolysis and structural features of lignin before and after hydrothermal treatment. Energy Convers. Manage. 155, 58-67.

Lischeske, J.J., Crawford, N.C., Kuhn, E., Nagle, N.J., Schell, D.J., Tucker, M.P., McMillan, J.D., Wolfrum, E.J., 2016. Assessing pretreatment reactor scaling through empirical analysis. Biotechnol. Biofuels 9, 213.

Liu, C., Wyman, C.E., 2003. The effect of flow rate of compressed hot water on xylan, lignin, and total mass removal from corn stover. Ind. Eng. Chem. Res. 42, 5409-5416.

Liu, C., Wyman, C.E. 2005. Partial flow of compressed-hot water through corn stover to enhance hemicellulose sugar recovery and enzymatic digestibility of cellulose. Bioresour. Technol. 96, 1978-1985.

Ma, X.J., Cao, S.L., Lin, L., Luo, X.L., Hu, H.C., Chen, L.H., Huang, L.L., 2013. Hydrothermal pretreatment of bamboo and cellulose degradation. Bioresour. Technol. 148, 408-413.

Ma, J., Zhang, X., Zhou, X., Xu, F., 2014. Revealing the changes in topochemical characteristics of poplar cell wall during hydrothermal pretreatment. Bioenergy. Res. 7 , 1358-1368.

Ma, J., Ji, Z., Chen, J.C., Zhou, X., Kim, Y.S., Xu, F., 2015. The mechanism of xylans removal during hydrothermal pretreatment of poplar fibers investigated by immunogold labeling. Planta. 242, 327-337.

Maroušek, J., Kawamitsu, Y., Ueno, M., Kondo, Y., L. Kolář., 2012. Methods for improving methane yield from rye straw. Appl. Eng. Agric. 28, 747-755.

Michelin, M., Ruiz, H.A., Polizeli, M. de L.T.M., Teixeira, J.A., 2018. Multi-step approach to add value to corncob: Production of biomass-degrading enzymes, lignin and fermentable sugars. Bioresour. Technol. 247, 582-590.

Miléo, P.C., Oliveira, M.F., Luz, S.M., Rocha, G.J., Gonçalves, A.R., 2016. Thermal and chemical characterization of sugarcane bagasse cellulose/lignin-reinforced composites. Polym. Bull. 73, 3163-3174.

Mittal, A., Chatterjee, S.G., Scott, G.M., Amidon, T.E., 2009. Modeling xylan solubilization during autohydrolysis of sugar maple and aspen wood chips: Reaction kinetics and mass transfer. Chem. Eng. Sci. 64, 3031-3041.

Mok, W.S.L., Antal, M.J., 1992. Uncatalyzed solvolysis of whole biomass hemicellulose by hot compressed liquid water. Ind. Eng. Chem. Res. 31, 1157-1161.

Mosbec h, C., Holck, J., Meyer, A.S., Agger, J.W., 2018. The natural catalytic function of $\mathrm{CuGE}$ glucuronoyl esterase in hydrolysis of genuine lignin-carbohydrate complexes from birch. Biotechnol. Biofuels. 11, 71.

Muzzy, J.D., Roberts, R.S., Fieber, C.A., Faass, G.S., Mann, T.M., 1983. Pretreatment of hardwood by continuous steam hydrolysis. In: Soltes J. (Ed.) Wood and Agricultural Residues. Elsevier Inc. New York. US.

Nachenius, R.W., van de Wardt, T.A., Ronsse, F., Prins, W., 2015. Residence time 
distributions of coarse biomass particles in a screw conveyor reactor. Fuel Process. Technol. 130, 87-95.

Nakanishi, S.C., Nascimento, V.M., Rabelo, S.C., Sampaio, I.L.M., Junqueira, T.L., Rocha, G.J.M., 2018. Comparative material balances and preliminary technical analysis of the pilot scale sugarcane bagasse alkaline pretreatment to $2 \mathrm{G}$ ethanol production. Ind. Crops Prod. 120, 187-197.

Nascimento, V.M., Rossell, C.E.V., de Moraes Rocha, G.J., 2017. Scale-Up Hydrothermal Pretreatment of Sugarcane Bagasse and Straw for Second-Generation Ethanol Production. In: Ruiz, H.A., Hedegaard Thomsen, M., Trajano, H.L. (Eds.), Hydrothermal Processing in Biorefineries: Production of Bioethanol and High AddedValue Compounds of Second and Third Generation Biomass. Springer International Publishing, Cham, pp. 377-388.

Nieder-Heitmann, M., Haigh, K., Louw, J., Görgens, J. F., 2019. Economic evaluation and comparison of succinic acid and electricity co-production from sugarcane bagasse and trash lignocelluloses in a biorefinery, using different pretreatment methods: dilute acid (H2SO4), alkaline $(\mathrm{NaOH})$, organosolv, ammonia fibre expansion (AFEX ${ }^{\mathrm{TM}}$ ), steam explosion (STEX), and wet oxidation. Biofuels, Bioprod. Biorefin. In press. doi. org/10.1002/bbb.2020.

Overend, R., Chornet, E., Gascoigne, J.A., 1987. Fractionation of lignocellulosics by steam-aqueous pretreatments. Philos. Trans. R. Soc. A. 321, 523-536.

Pedersen, M., Meyer, A.S., 2010. Lignocellulose pretreatment severity - relating pH to biomatrix opening. New Biotechnol. 27, 739-750.

Pedersen, M., Viksø-Nielsen, A., Meyer, A.S., 2010. Monosaccharide yields and lignin removal from wheat straw in response to catalyst type and $\mathrm{pH}$ during mild thermal pretreatment. Process. Biochem. 45, 1181-1186.

Peleteiro, S., Santos, V., Garrote, G., Parajó, J.C., 2016. Furfural production from Eucalyptus wood using an acidic ionic liquid. Carbohydr. Polym. 146, 20-25.

Pereira, S.C., Maehara, L., Machado, C.M.M., Farinas, C.S., 2015. 2G ethanol from the whole sugarcane lignocellulosic biomass. Biotechnol. Biofuels 8, 44.

Petersen, M.Ø., Larsen, J., Thomsen, M.H., 2009. Optimization of hydrothermal pretreatment of wheat straw for production of bioethanol at low water consumption without addition of chemicals. Biomass Bioenergy. 33, 834-840.

Pielhop, T., Amgarten, J., von Rohr, P.R., Studer, M.H., 2016. Steam explosion pretreatment of softwood: the effect of the explosive decompression on enzymatic digestibility. Biotechnol. Biofuels. 9, 152.

Pimienta, J.A.P., Papa, G., Rodriguez, A., Barcelos, C.A., Liang, L., Stavila, V., Sanchez, A., Gladden, J.M., Simmons, B.A., 2019. Pilot-scale hydrothermal pretreatment and optimized saccharification enables bisabolene production from multiple feedstocks. Green Chem. 21, 3152-3164.

Pino, M.S., Rodríguez-Jasso, R.M., Michelin, M., Flores-Gallegos, A.C., MoralesRodriguez, R., Teixeira, J.A., Ruiz, H.A., 2018. Bioreactor design for enzymatic hydrolysis of biomass under the biorefinery concept. Chem. Eng. J. 347, 119-136.

Pino, M.S., Rodríguez-Jasso, R.M., Michelin, M., Ruiz, H.A., 2019. Enhancement and modeling of enzymatic hydrolysis on cellulose from agave bagasse hydrothermally pretreated in a horizontal bioreactor. Carbohydr. Polym. 211, 349-359.

Prunescu, R.M., Blanke, M., Jakobsen, J.G., Sin, G., 2015. Dynamic modeling and validation of a biomass hydrothermal pretreatment process-a demonstration scale study. AIChE. 61, 4235-4250.

Pronyk, C., Mazza, G., 2010. Kinetic modeling of hemicellulose hydrolysis from Triticale straw in a pressurized low polarity water flow-through reactor. Ind. Eng. Chem. Res. $49,6367-6375$.

Pu, Y., Hu, F., Huang, F., Davison, B.H., Ragauskas, A.J., 2013. Assessing the molecular structure basis for biomass recalcitrance during dilute acid and hydrothermal pretreatments. Biotechnol. Biofuels. 6, 15.

Rainey, T.J., Covey, G., 2016. Pulp and paper production from sugarcane bagasse. In: O'Hara, I.M., Mundree, S.G. (Eds.), Sugarcane-Based Biofuels and Bioproducts. John Wiley \& Sons Inc, Hoboken, NJ, USA, pp. 259-280.

Rasmussen, H., Sørensen, H.R., Meyer, A.S., 2014. Formation of degradation compounds from lignocellulosic biomass in the biorefinery: sugar reaction mechanisms. Carbohydr. Res. 385, 45-57.

Rasmussen, H., Tanner, D., Sørensen, H.R., Meyer, A.S., 2017a. New degradation compounds from lignocellulosic biomass pretreatment: routes for formation of potent oligophenolic enzyme inhibitors. Green Chem. 19, 464-473.

Rasmussen, H., Sørensen, H.R., Tanner, D., Meyer, A.S., 2017b. New pentose dimers with bicyclic moieties from pretreated biomass. RSC Adv. 7, 5206-5213.

Reynolds, W., Singer, H., Schug, S., Smirnova, I., 2015. Hydrothermal flow-through treatment of wheat-straw: Detailed characterization of fixed-bed properties and axial dispersion. Chem. Eng. J. 281, 696-703.

Reynolds, W., Smirnova, I., 2018. Hydrothermal flow-through treatment of wheat straw: Coupled heat and mass transfer modeling with changing bed properties. J. Supercrit. Fluids 133, 625-639.

Reynolds, W., Conrad, M., Mbeukem, S., Stank, R., Smirnova, I., 2019. Pressure drop, mechanic deformation, stabilization and scale-up of wheat straw fixed-beds during hydrothermal pretreatment: Experiments and modeling. Chem. Eng. J. 360, 1587-1600.

Rivas, S., Vila, C., Alonso, J.L., Santos, V., Paraj V z, J.C., Leahy, J.J., 2019. Biorefinery processes for the valorization of Miscanthus polysaccharides: from constituent sugars to platform chemicals. Ind. Crops Prod. 134, 309-317.

Rocha, G.J.M., Gonçalves, A.R., Oliveira, B.R., Olivares, E.G., Rossell, C.E.V., 2012. Steam explosion pretreatment reproduction and alkaline delignification reactions performed on a pilot scale with sugarcane bagasse for bioethanol production. Ind. Crops Prod. 35, 274-279.

Rocha, G.J.M., Gonçalves, A.R., Nakanishi, S.C., Nascimento, V.M., Silva, V.F.N., 2015 Pilot scale steam explosion and diluted sulfuric acid pretreatments: Comparative study aiming the sugarcane bagasse saccharification. Ind. Crops Prod. 74, 810-816.

Rodriguez, F., Sanchez, A., Parra, C., 2017. Role of steam explosion on enzymatic digestibility, xylan extraction and lignin release from Lignocellulosic biomass. ACS Sustainable Chem. Eng. 56, 5234-5240.

Romaní, A., Garrote, G., Alonso, J.L., Parajó, J.C., 2010. Bioethanol production from hydrothermally pretreated Eucalyptus globulus wood. Bioresour. Technol. 101, 8706-8712.

Romaní, A., Garrote, G., López, F., Carlos, J., 2011. Eucalyptus globulus wood fractionation by autohydrolysis and organosolv delignification. Bioresour. Technol. 102, 5896-5904.

Romaní, A., Garrote, G., Parajó, J.C., 2012. Bioethanol production from autohydrolyzed Eucalyptus globulus by simultaneous saccharification and fermentation operating at high solids loading. Fuel 94, 305-312.

Rossner, A., Parra, C., 2017. Pilot plant design and operation using a hydrothermal pretreatment: bioenercel experience. In: Ruiz, H.A., Thomsen, M.H., Trajano, H.L. (Eds.), Hydrothermal Processing in Biorefineries. Springer International Publishing, Switzerland, pp. 389-400.

Ruiz, H.A., Ruzene, D.S., Silva, D.P., Quintas, M.A.C., Vicente, A.A., Teixeira, J.A., 2011a. Evaluation of a hydrothermal process for pretreatment of wheat straw-effect of particle size and process conditions. J. Chem. Technol. Biotechnol. 86, 88-94.

Ruiz, H.A., Ruzene, D.S., Silva, D.P., Da Silva, F.F.M., Vicente, A.A., Teixeira, J.A., 2011 b. Development and characterization of an environmentally friendly process sequence (autohydrolysis and organosolv) for wheat straw delignification. Appl. Biochem. Biotechnol. 164, 629-641.

Ruiz, H.A., Vicente, A.A., Teixeira, J.A., 2012a. Kinetic modeling of enzymatic saccharification using wheat straw pretreated under autohydrolysis and organosolv process. Ind. Crops Prod. 36, 100-107.

Ruiz, H.A., Silva, P.D., Ruzene, D.S., Lime, L.F., Vicente, A.A., Teixeira, J.A., 2012b. Bioethanol production from hydrothermal pretreatment wheat straw by flocculating Saccharomyces cerevisiae strain- Effect of process conditions. Fuel 95, 528-536.

Ruiz, H.A., Rodríguez-Jasso, R.M., Fernandes, B.D., Vicente, A.A., Teixeira, J.A., 2013a. Hydrothermal processing, as an alternative for upgrading agricultural residues and marine biomass according to the biorefinery concept: a review. Renew. Sust. Energ. Rev. 21, 35-51.

Ruiz, H.A., Cerqueira, M.A., Silva, H.D., Rodríguez-Jasso, R.M., Vicente, A.A., Teixeira, J.A., 2013b. Biorefinery valorization of autohydrolysis wheat straw hemicellulose to be applied in a polymer-blend film. Carbohydr. Polym. 92, 2154-2162.

Ruiz, H.A., Thomsen, M.H., Trajano, H.L., 2017. Hydrothermal processing in Biorefineries. Springer International Publishing, Cham, Switzerland.

Samuel, R., Cao, S., Das, B.K., Hu, F., Pu, Y., Ragauskas, A.J., 2013. Investigation of the fate of poplar lignin during autohydrolysis pretreatment to understand the biomass recalcitrance. RSC Adv. 3, 5305-5309.

Schmidt, L.M., Pérez Martínez, V., Kaltschmitt, M., 2018. Solvent-free lignin recovered by thermal-enzymatic treatment using fixed-bed reactor technology - Economic assessment. Bioresour. Technol. 268, 382-392.

Selig, M.J., Viamajala, S., Decker, S.R., Tucker, M.P., Himmel, M.E., Vinzant, T.B., 2007. Deposition of lignin droplets produced during dilute acid pretreatment of maize stems retards enzymatic hydrolysis of cellulose. Biotechnol. Prog. 23, 1333-1339.

Shekiro III, J., Kuhn, E.M., Nagle, N.J., Tucker, M.P., Elander, R.T., Schell, D.J., 2014. Characterization of pilot-scale dilute acid pretreatment performance using deacetylated corn stover. Biotechnol. Biofuels. 7, 23.

Sievers, D.A., Stickel, J.J., 2018. Modeling residence-time distribution in horizontal screw hydrolysis reactors. Chem. Eng. Sci. 175, 396-404.

Singh, A., Jasso, R.M.R., Gonzalez-Gloria, K.D., Rosales, M., Cerda, R.B., Aguilar, C.N., Singhania, R.R., Ruiz, H.A., 2019. The enzyme biorefinery platform for advanced biofuels production. Bioresour. Technol. Rep. 7, 100257.

Steinbach, D., Kruse, A., Sauer, J., 2017. Pretreatment technologies of lignocellulosic biomass in water in view of furfural and 5-hydroxymethylfurfural production - A review. Biomass Conv. Bioref. 7, 247-274.

Sun, S.N., Cao, X.F., Li, H.Y., Xu, F., Sun, R.C., 2014a. Structural characterization of residual hemicelluloses from hydrothermal pretreated Eucalyptus fiber. Int. J. Biol. Macromol. 69, 158-164.

Sun, S.N., Cao, X.F., Sun, S.L., Xu, F., Song, X.L., Sun, R.C., Jones, G.L., 2014b. Improving the enzymatic hydrolysis of thermo-mechanical fiber from Eucalyptus urophylla by a combination of hydrothermal pretreatment and alkali fractionation. Biotechnol. Biofuels. 7, 116.

Sun, S.L., Sun, S.N., Wen, J.L., Zhang, X.M., Peng, F., Sun, R.C., 2015a. Assessment of integrated process based on hydrothermal and alkaline treatments for enzymatic saccharification of sweet sorghum stems. Bioresour. Technol. 175, 473-479.

Sun, S., Wen, J., Sun, S., Sun, R.C., 2015b. Systematic evaluation of the degraded products evolved from the hydrothermal pretreatment of sweet sorghum stems. Biotechnol. Biofuels. 8, 37.

Sun, S., Sun, S., Cao, X., Sun, R., 2016. The role of pretreatment in improving the enzymatic hydrolysis of lignocellulosic materials. Bioresour. Technol. 199, 49-58.

Tao, L., Aden, A., Elander, R.T., Pallapolu, V.R., Lee, Y.Y., Garlock, R.J., Balan, V., Dale, B., Kim, Y., Mosier, N.S., Ladish, M.R., Falls, M., Holtzapple, M.T., Sierra, R., Shi, J., Ebrick, M., Redmond, T., Yang, B., Wyman, C.E., Hames, B., Thomas, S., Warner, R.E., 2011. Process and technoeconomic analysis of leading pretreatment technologies for lignocellulosic ethanol production using switchgrass. Bioresour. Technol. $102,11105-11114$.

Thomsen, M.H., Thygesen, A., Jorgensen, H., Larsen, J., Christensen, B.H., Thomsen, A.B., 2006. Preliminary results on optimization of pilot scale pretreatment of wheat straw used in coproduction of bioethanol and electricity. Appl. Biochem. Biotechnol. 129-132, 448-460.

Torres, A.I., Ashraf, M.T., Chaturvedi, T., Schmidt, J.E., Stephanopoulos, G., 2017. Hydrothermal pretreatment: Process modeling and economic assessment within the framework of biorefinery processes. In: Ruiz, H.A., Thomsen, M.H., Trajano, H.L. (Eds.), Hydrothermal Processing in Biorefineries. Springer International Publishing, 
Switzerland, pp. 207-235.

Torres-Mayanga, P.C., Azambuja, S.P.H., Tyufekchiev, M., Tompsett, G.A., Timko, M.T., Goldbeck, R., Rostagno, M.A., Forster-Carneiro, T., 2019. Subcritical water hydrolysis of brewer's spent grains: Selective production of hemicellulosic sugars (C-5 sugars). J. Supercrit. Fluids. 145, 19-30.

Wang, W., Chen, X., Donohoe, B.S., Ciesielski, P.N., Katahira, R., Kuhl, E.M., Kafle, K. Lee, C.M., Park, S., Kim, S.H., Tucker, M.P., Himmel, M.E., Johnson, D.K., 2014. Effect of mechanical disruption on the effectiveness of three reactors used for dilute acid pretreatment of corn stover Part 1: chemical and physical substrate analysis. Biotechnol. Biofuels 7, 57.

Wang, Z.W., Zhu, M.Q., Li, M.F., Wang, J.Q., Wei, Q., Sun, R.C., 2016. Comprehensive evaluation of the liquid fraction during the hydrothermal treatment of rapeseed straw. Biotechnol. Biofuels. 9, 142.

Wayman, M., Parekh, S., Chornet, E., Overend, R.P., 1986. SO $\mathrm{S}_{2}$-catalysed prehydrolysis of coniferous wood for ethanol production. Biotechnol. Lett. 8, 749-752.

Wikberg, H., Grönqvist, S., Niemi, P., Mikkelson, A, Siika-aho, M., Kanerva, H., Käsper, A., Tamminen, T., 2017. Hydrothermal treatment followed by enzymatic hydrolysis and hydrothermal carbonization as means to valorise agro- and forest-based biomass residues. Bioresour. Technol. 235, 70-78.

Xiao, L.P., Shi, Z.J., Xu, F., Sun, R.C., 2012. Characterization of mwls from Tamarix ramosissima isolated before and after hydrothermal treatment by spectroscopical and wet chemical methods. Holzforschung. 66, 295.

Xiao, L.P., Shi, Z.J., Xu, F., Sun, R.C., 2013. Hydrothermal treatment and enzymatic hydrolysis of Tamarix ramosissima: Evaluation of the process as a conversion method in a biorefinery concept. Bioresour. Technol. 135, 73-81.

Xiao, X., Bian, J., Li, M.F., Xu, H., Xiao, B., Sun, R.C., 2014. Enhanced enzymatic hydrolysis of bamboo (Dendrocalamus giganteus munro) culm by hydrothermal pretreatment. Bioresour. Technol. 159, 41-47.

Yang, B., Wyman, C.E., 2004. Effect of xylan and lignin removal by batch and flowthrough pretreatment on the enzymatic digestibility of corn stover cellulose. Biotechnol. Bioeng. 86, 88-98.

Yu, Y., Wu, H., 2010. Significant differences in the hydrolysis behavior of amorphous and crystalline portions within microcrystalline cellulose in hot-compressed water. Ind. Eng. Chem. Res. 49, 3902-3909.

Zabed, H., Sahu, J.N., Boyce, A.N., Faruq, G., 2016. Fuel ethanol production from lignocellulosic biomass: An overview on feedstocks and technological approaches. Renew. Sust. Energ. Rev. 66, 751-774.

Zanuso, E., Lara-Flores, A.A., Aguilar, D.L., Velazquez-Lucio, J., Aguilar, C.N., RodríguezJasso, R.M., Ruiz, H.A., 2017. Kinetic modeling, operational conditions, and biorefinery products from hemicellulose: depolymerization and solubilization during hydrothermal processing. In: Ruiz, H.A., Thomsen, M.H., Trajano, H.L. (Eds.), Hydrothermal Processing in Biorefineries. Springer International Publishing, Switzerland, pp. 141-160.

Zeitsch, K.J., 2000. The chemistry and technology of furfural and its many by-products. Elsevier Science, The Netherkands.

Zhang, W., You, Y., Lei, F., Li, P., Jiang, J., 2018. Acetyl-assisted autohydrolysis of sugarcane bagasse for the production of xylo-oligosaccharides without additional chemicals. Bioresour. Technol. 265, 387-393.

Zhuang, X., Wang, W., Yu, Q., Oi, W., Wang, Q., Tan, X., Zhou, G., Yuan, Z., 2016. Liquid hot water pretreatment of lignocellulosic biomass for bioethanol production accompanying with high valuable products. Bioresour. Technol. 199, 68-75. 